\title{
A Characterization of the Nonresidential Fenestration Market
}

\section{Nonresidential Fenestration Market Research}

July 25, 2002

Prepared for

Lawrence Berkeley National Laboratory (LBNL)

Northwest Energy Efficiency Alliance (NEEA)

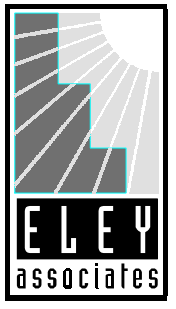

142 Minna Street

San Francisco, California 94105

(415) 9571977 Voice

(415) $9571381 \mathrm{Fax}$

www.eley.com 


\section{Acknowledgements}

Eley Associates prepared this report under contract to the Lawrence Berkeley National Laboratory (LBNL. The Northwest Energy Efficiency Alliance (NEEA) also provided financial support to Eley Associates for the completion of this project.

The authours would like to thank and acknowledge the contributions of their colleagues. Kimberly Got (Eley Associates) was the copy editor and also assisted with the graphics production. Joe Eto (LBNL), John Jennings (NEEA), and Jeff Harris (NEEA) also reviewed the document and provided valuable comments.

An outside review group contributed significantly to the development of this document through their review and feedback. This group included Carl Wagus (American Architectural Manufacturers Association), Jim Benney (National Fenestration Rating Council), and John Hogan (City of Seattle). Finally, special acknowledgement must be given to the many industry representatives interviewed who volunteered their time to provide valuable insight into the fenestration industry contained in this report.

This work was supported by the Assistant Secretary for Energy Efficiency and Renewable Energy, Building Technologies Program, of the U.S. Department of Energy under Contract No. DE-AC03-76SF00098. 


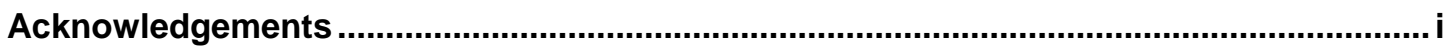

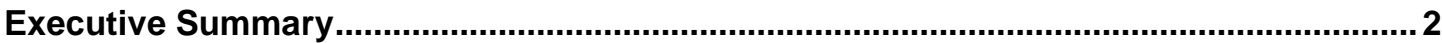

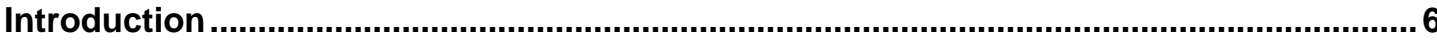

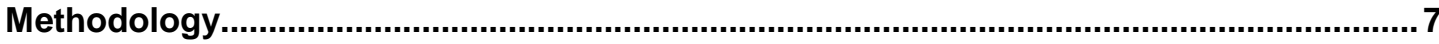

The Supply Side of the Market

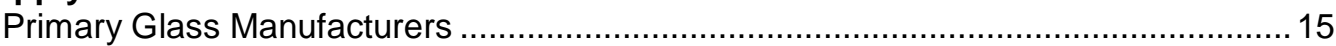

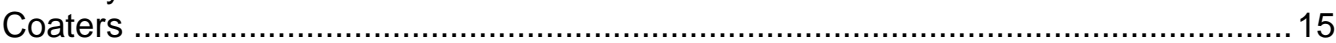

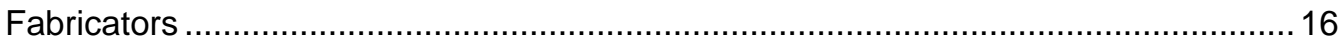

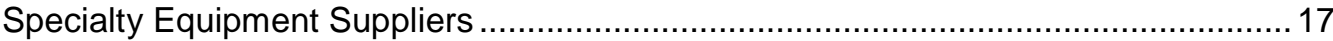

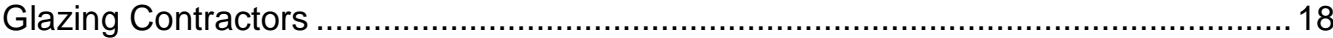

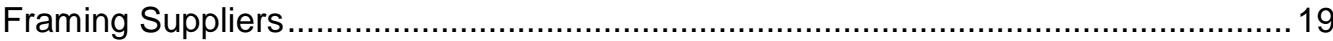

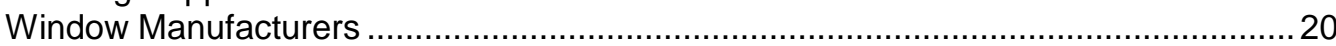

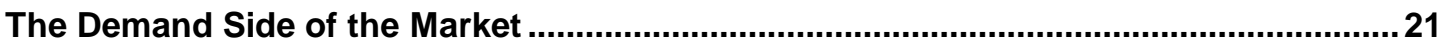

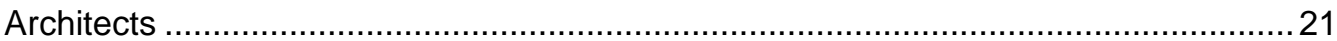

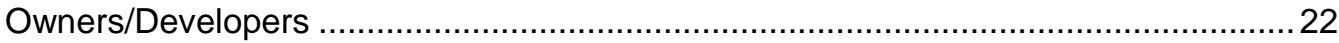

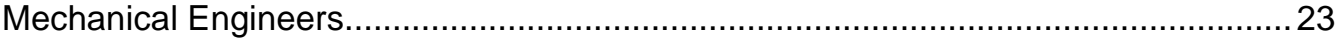

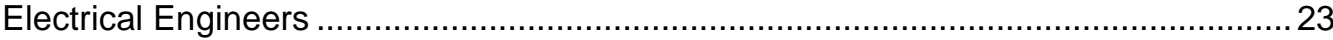

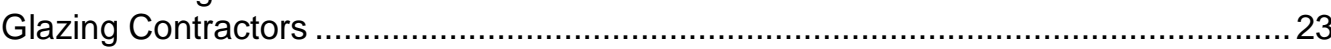

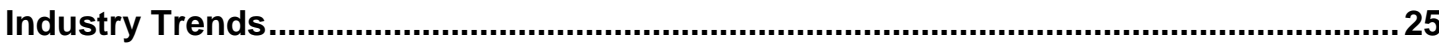

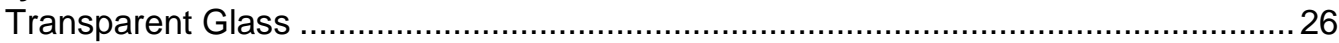

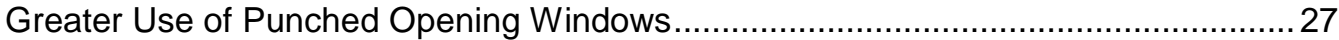

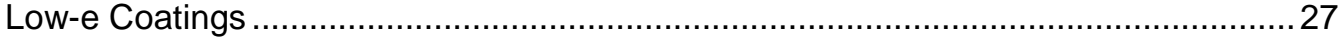

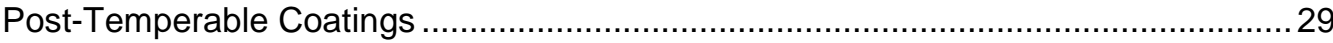

Thermally Broken and Thermally Improved Frames ................................................ 30

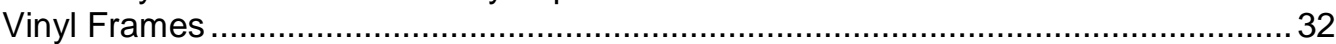

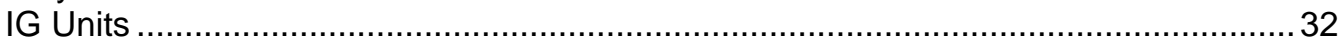

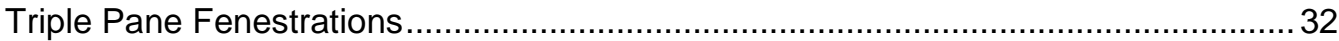

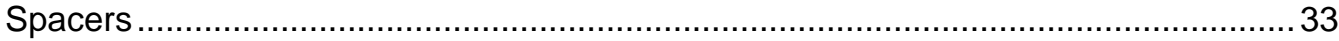

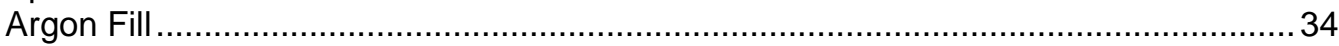

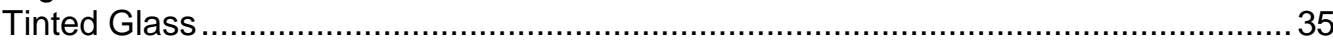

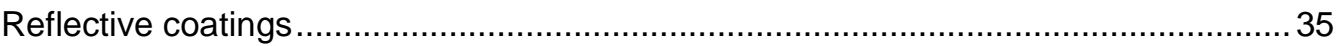

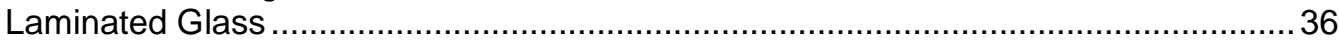

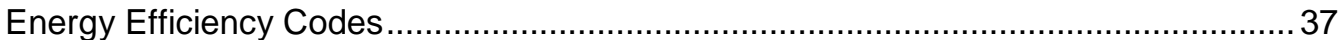

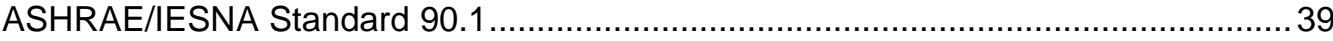

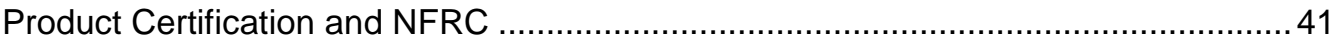

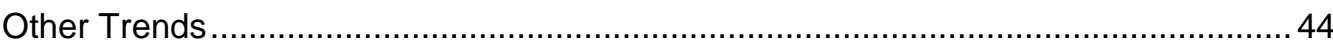

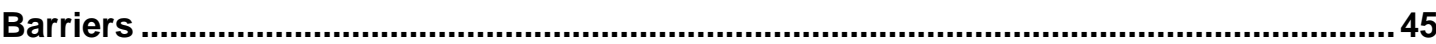

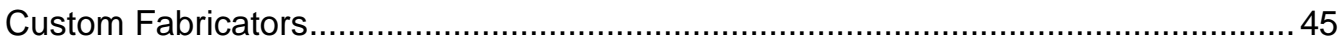

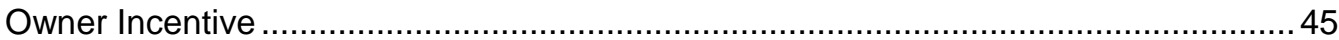

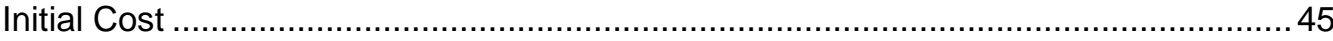

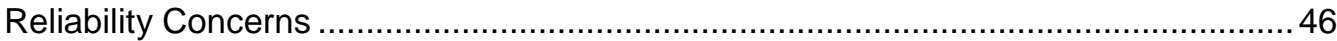

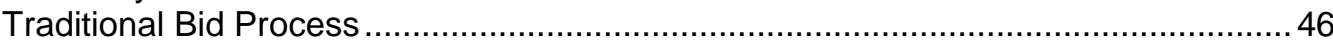

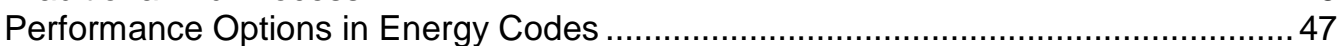

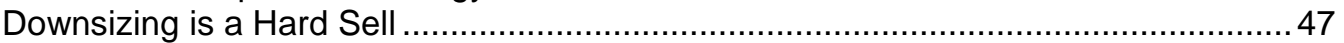

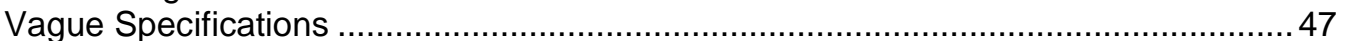

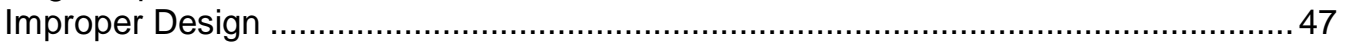

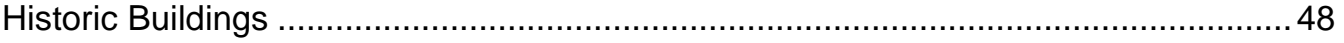

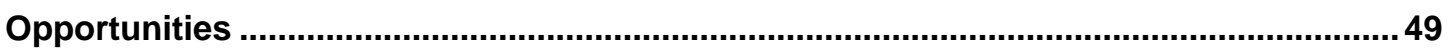

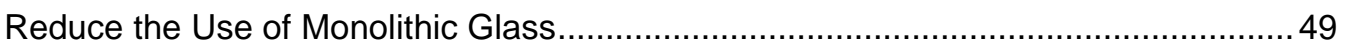

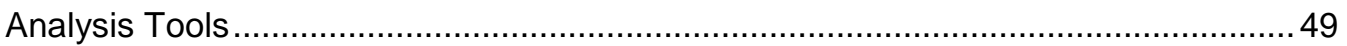

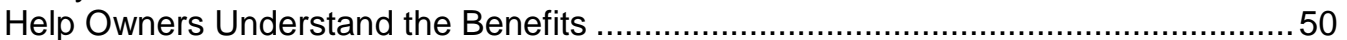

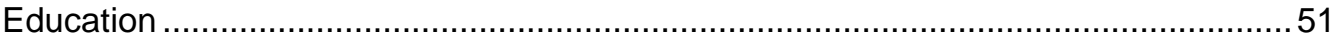




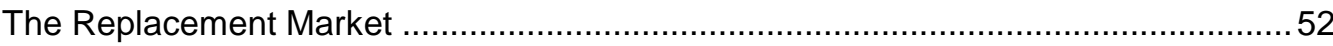

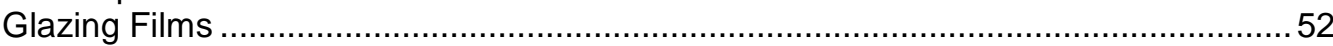

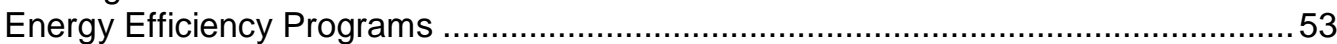

Better Communication Among the Design Team ...................................................... 53

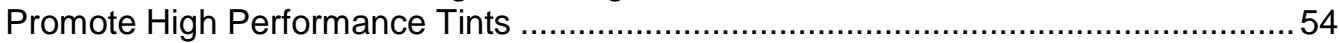

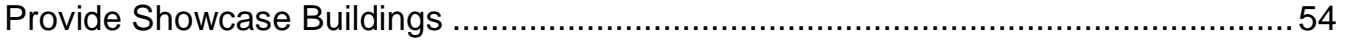

Address Energy Efficiency at the Planning Stage .................................................5 54

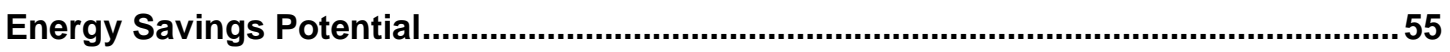

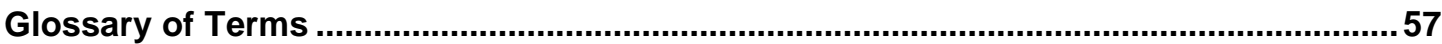

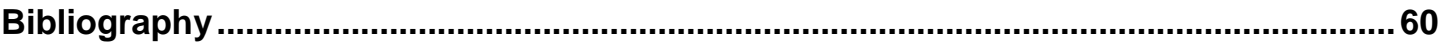

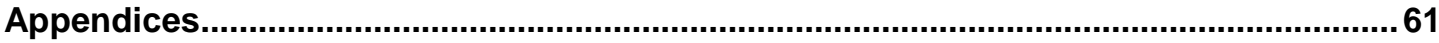

Appendix A -NFRC Rating and Certification Procedures for Site-Built Fenestration .. 61

Appendix B - Fenestration Product Flows in the Pacific Northwest.............................65

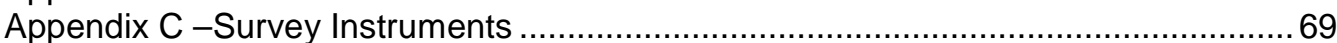

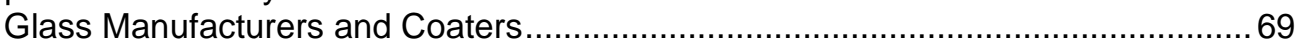

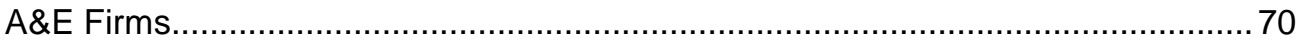

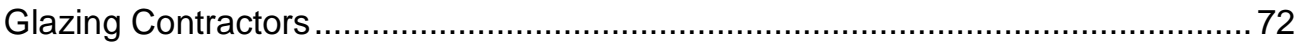

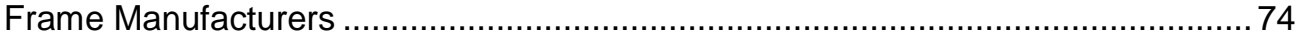

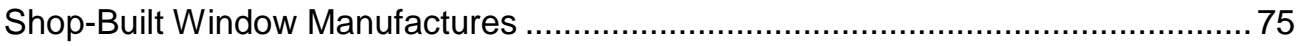

Laminate and Applied Film Manufactures ....................................................... 77

\section{Figures}

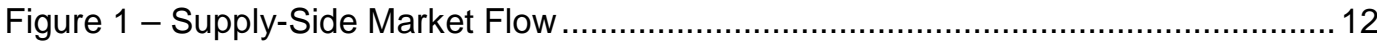

Figure 2 - ASHRAE 90.1-1999 Fenestration U-factor Requirements ...........................40 40

Figure 3 - ASHRAE 90.1-1999 Fenestration SHGC Requirements (0.2-0.3 WWR) ....... 40

Figure 4 - Current Use of ASHRAE Standard by State ...............................................4 41

Figure 5 - Heating and Cooling Loads Imposed by Nonresidential Glazing ....................55

Figure 6 - Pacific Northwest Supply-Side Market Flow ............................................... 66

\section{Tables}

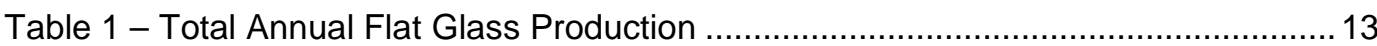

Table 2 - PGM Output of Nonresidential Fenestration (millions of $\mathrm{ft}^{2}$ ) ...........................13

Table 3 - Nonresidential Fenestration Input to Glazing Contractors (millions of $\mathrm{ft}^{2}$ ) ........14

Table 4 - Total Nonresidential Fenestration (millions of $\mathrm{ft}^{2}$ ) ......................................... 14

Table 5 - Projected Costs for NFRC Testing and Labeling of Glazed Wall Systems ...... 64

Table 6 - PGM Output of Nonresidential Fenestration (millions of $\mathrm{ft}^{2}$ ) ...........................6 67

Table 7 - Nonresidential Fenestration Input to Glazing Contractors (millions of $\mathrm{ft}^{2}$ ) ........66

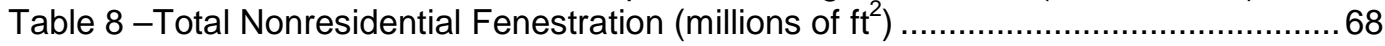




\section{Executive Summary}

The U.S. glass industry is a $\$ 27$ billion enterprise ${ }^{1}$ with both large producers and small firms playing pivotal roles in the industry. While most sectors of the glass industry have restructured and consolidated in the past 20 years, the industry still employs 150,000 workers. ${ }^{2}$ Nonresidential glazing accounts for approximately $18 \%$ of overall U.S. glass production. ${ }^{3}$ In 1999, nonresidential glazing was supplied to approximately 2.2 billion $\mathrm{ft}^{2}$ of new construction and additions. ${ }^{4}$ That same year, nonresidential glazing was also supplied to approximately 1.1 billion $\mathrm{ft}^{2}$ of remodeling construction. ${ }^{5}$

The nonresidential fenestration industry begins with the primary glass manufacturers (PGMs), who manufacture flat glass. There are only six PGMs operating nearly 30 manufacturing plants nationally. PGMs are limited in number partly because of the large investment required to construct a float line and the need for a strong customer base to buy the product. The flat glass product that leaves the float line can be clear or tinted and may have a pyrolytic coating applied to one surface of the glass. Flat glass may then go to a coater, which may be part of the PGMs' operation or a separate, independent entity. Coaters use a high technology sputter process to apply a thin (usually multi-layer) coating to the surface of the glass. Both pyrolytic and sputter coatings can be applied to either clear or tinted glass. The coatings may have many properties such as a low emittance (low-e) and/or low transmittance (high reflectance). After glass is coated, it moves to the fabricator who assembles it into an insulated glass (IG) unit. ${ }^{6}$ The IG units then go to either a window manufacturer (shop-built windows) or to a glazing contractor (site-built windows).

1 U.S. Department of Energy. "Glass Industry Analysis Brief." www.eia.doe.gov/emeu/mecs/iab/glass/index.HTML, Aug. 2000.

2 Ibid.

3 Industry Statistics. Glass Magazine, Aug. 2000. Data for other glazing markets (residential, automotive, and specialty) are located in Table 1.

4 Ducker Research Company. "The Distribution of Residential Doors and Windows in the 1999 U.S. Market." April 2000.

5 Ibid.

$6 \quad$ IG unit is an industry term that is generally used to represent double pane windows. 
Some of the PGMs make the glass, coat it, and fabricate it into IG units. Other PGMs focus their business on providing flat glass products to independent coaters and fabricators. Independent coaters (non-PGMs) also fabricate IG units. Independent fabricators (non-PGMs and non-coaters) buy flat glass directly from PGMs or independent coaters, stock it in their shops, and fabricate IG units or monolithic ${ }^{7}$ panels for glazing contractors. Independent fabricators, who often keep stock of common glazing types, require a much shorter lead-time. This is one of the advantages independent fabricators bring to the industry.

The product flow for nonresidential fenestration products can follow one of several channels. The production channel for manufactured windows includes the PGM, the coater, and the fabricator before the IG unit is delivered to the window manufacturer. The production channel for storefront fenestration usually includes the PGM and an independent fabricator who puts together IG units for a local glazing contractor.

The barriers to energy efficiency are different for each channel and the opportunities for changing the market vary. For instance, shop-built punched opening windows can be very efficient: the saturation of low-e coatings and other high performance features are higher, and products are consistently tested and labeled, so that consumers can see what they are buying. At the other extreme, the supply channel for site-built storefront fenestration (especially small projects) results in very limited use of energy-efficient features. Local fabricators can only stock a fraction of the various glazing types produced by the PGMs, and tend to only stock glazing that is in high demand. Glazing contractors working on smaller projects generally work with local fabricators and rarely work directly with PGMs or coaters that have the technology for advanced coatings and other energyefficient features. The fenestration types stocked by local fabricators determine what energy-efficient glass is available. The industry is aware of these limitations and new technologies (for example post-temperable coatings) are emerging that could improve energy-efficient options in traditionally limited supply channels.

Aesthetic trends are having a rippling effect on the nonresidential market. Architects want clearer-looking glass and the market is moving quickly toward glazing options with high visible light transmission. This is increasing demand for high performance tints and low-e coatings, which offer high visible light transmission but also reduce solar heat gain.

7 Monolithic is an industry term used to represent single pane windows. 
Certain other technologies, such as reflective coatings, have remained static or are currently declining.

Sputter low-e coatings are a very cost-effective, energy-efficient technology for most of the marketing and production channels. Most shop-built punched opening windows have this technology, and it is becoming more common in site-built applications. High performance fenestration that includes low-e coatings are very prevalent on larger sitebuilt projects, but concern over long lead times is a major barrier which is keeping sputter low-e coatings out of many smaller site-built projects. Concern over glazing clarity and visibility for the shopper also seems to be preventing the use of low-e coatings (both sputter and pyrolytic) on retail storefront applications, though there are large retail projects dating from the late 1980 s that have successfully used low-e coatings on storefront fenestration.

Initial cost is a major barrier preventing greater use of high performance technologies, even though the California electricity crisis has heightened awareness of energy-efficient fenestration. Many in the industry believe that codes are the only way to motivate firstcost orientated developers to specify energy efficiency technologies that may have a higher initial cost. Developers commonly sell buildings after construction is completed and are less motivated to invest in technologies that reduce operating costs. While the fenestration industry supports stricter energy efficiency codes, it needs codes that are simple, straightforward, and unambiguous.

Architects have significant influence over the location, area, and type of fenestration in nonresidential buildings. Some stress the need for better analysis tools to help them quantify the benefits of energy-efficient design. The level of uncertainty in performance and payback makes owners wary of materials with a higher initial cost. Overall, the architectural community favors energy-efficient design and will push for energy-efficient fenestration if they are armed with the proper information to persuade clients.

The greatest room for improvement of energy efficiency is in small-to-medium projects that receive glass through the independent fabricator channel. The majority of low performance glass is obtained through this independent fabricator channel. Industry groups involved with smaller projects receive the least amount of education from primary glass manufacturers and have the least amount of capital for energy efficiency upgrades. These smaller projects also must quickly deliver products to glazing contractors, which limits the type of technologies that can be supplied in adequate time. 
Interviewees identify certain aspects of the fenestration market that are restricting the use of energy-efficient technologies. Addressing these restrictions could significantly improve building energy efficiency. Some of these include:

- The use of single pane glass in new buildings. Along with being energy inefficient, most low-e coatings cannot be placed on single pane glass.

- The lack of availability of high performance glass from local fabricators. Small construction jobs obtain glass from a local fabricator. Potential logistical problems make glazing contractors wary of ordering glass types that their fabricators do not commonly stock.

- Minimal use of energy-efficient fenestration in retrofit projects. Fenestration very similar to the existing fenestration is specified in a retrofit project. The existing fenestration in a retrofit project generally consists of old windows that are energy inefficient in design.

Interviewees also suggest ways to increase the market penetration of energy-efficient fenestration. Some of these include:

- Design energy efficiency programs that can provide rebates to minimize the higher initial cost of energy-efficient fenestration.

- Provide analysis tools and showcase buildings that architects can use to educate clients about the costs and benefits of energy-efficient technologies.

- Educate building maintenance executives about the availability of cost-effective, energy-efficient technologies when fenestration is being replaced in retrofit projects.

- Educate building maintenance executives about the use of glazing films when fenestration is not being replaced in retrofit projects. 


\section{Introduction}

The purpose of this report is to characterize the nonresidential fenestration market in order to better understand market barriers to, and opportunities for, energy-efficient fenestration products. In particular, the goal is to:

- Better understand how glazing products flow between industry groups.

- Identify major decision makers directing the product flow.

- Understand industry trends for certain technologies or products.

- Characterize the role of energy codes and standards in influencing industry trends.

- Assess the impact of product testing and certification programs on the industry.

The U.S. glass industry is a $\$ 27$ billion enterprise ${ }^{8}$ with both large producers and small firms playing pivotal roles in the industry. While most sectors of the glass industry have restructured and consolidated in the past 20 years, the industry still employs 150,000 workers. ${ }^{9}$ Nonresidential glazing accounts for approximately $18 \%$ of overall U.S. glass production. ${ }^{10}$ In 1999, nonresidential glazing was supplied to approximately 2.2 billion $\mathrm{ft}^{2}$ of new construction and additions. ${ }^{11}$ That same year, nonresidential glazing was also supplied to approximately 1.1 billion $\mathrm{ft}^{2}$ of remodeling construction. ${ }^{12}$ With an industry this large and complex, it is to be expected that many market participants can influence fenestration selection. If market barriers to the selection of high performance fenestration products are better understood, then the U. S. Department of Energy (USDOE), the Northwest Energy Efficiency Alliance (NEEA), and others can develop programs and policies that promote greater energy efficiency in commercial glazing products.

8 USDOE "Glass Industry Analysis Brief." www.eia.doe.gov/emeu/mecs/iab/glass/index.HTML, Aug. 2000.

9 Ibid.

10 Industry Statistics, Glass Magazine, Aug. 2000. Data for other glazing markets (residential, automotive, and specialty) is located in Table 1.

11 Ducker Research Company. "The Distribution of Residential Doors and Windows in the 1999 U.S. Market." April 2000.

12 Ibid. 


\section{Methodology}

Information for this report is primarily gathered through 70 telephone interviews conducted with various fenestration industry representatives during the period of July 2001 through October 2001. The approach is to gather supply-side information through interviews with glass manufacturers, glass coaters, fabricators, window manufacturers, and glazing contractors. Interviews with architects and engineers provide information on aesthetic trends, architectural needs, and other demand-side considerations. Interviewee selection is influenced by references from the project review group ${ }^{13}$ and from references given by other interviewees. Each interviewee is asked a series of predetermined questions specific to their field (see Appendix $\mathrm{C}$ ). All national regions are represented during the interview selection. By design, approximately $20 \%$ those interviewed are located in the Pacific Northwest.

All national glass manufactures and coaters are interviewed.

- Nine interviews are conducted with representatives from all six of the major U.S. primary glass manufacturers. These six primary glass manufacturers account for nearly $100 \%$ of the glass used in the U.S. nonresidential fenestration market.

- Four different representatives from two independent coating firms are interviewed. These two coating firms account for nearly all U.S. glass coating that is not performed by the primary glass manufacturers.

The other 57 interviews attempt to represent the hundreds of other industry players involved with nonresidential fenestration.

- Six fabricating firms are interviewed to represent the hundreds of fabricators throughout the country. The six firms interviewed include large national fabricators with fabrication sites throughout the country and small fabricators that serve a localized market.

13 Project review group includes Dariush Arasteh (LBNL), Phil Degens (NEEA), Charles Eley (Eley Associates), Carl Wagus (AAMA), Jim Benney (NFRC), and John Hogan (City of Seattle). 
- Twelve glazing contractor groups are interviewed. The glazing contractors interviewed cover regions throughout the country and represent approximately $15 \%$ of the glazing contractor market. Most of the glazing contractors interviewed represent larger firms that primarily work on medium-to-large projects.

- Architects from 16 different architecture firms throughout the country are interviewed. The firms interviewed include some of the largest firms in the industry, as well as smaller firms working in specific regions throughout the country. Together, the firms interviewed are involved with approximately $10 \%$ of U.S. nonresidential construction.

- Three major window manufacturers that serve the nonresidential market are interviewed, representing approximately $10 \%$ of the window manufacturing market.

- Five framing suppliers are interviewed. This represents a significant portion of the framing supplier industry, as all major framing suppliers are interviewed.

- Nine consultants and trade association members are interviewed to provide an overview and more general insight of the market.

- Four of the seven applied film and laminate manufactures are interviewed.

- One of two national firms that supply sputter coating equipment and a firm providing chemistry technology for pyrolytic coatings are interviewed.

Information garnered during the interviews is supplemented by industry data developed through a literature review. The industry data used is gathered from the following sources:

- Ducker Research Company. Information from Ducker is used to estimate the amount of glass and window types that end up in nonresidential buildings.

- U.S. Census Bureau. Bureau information is used to estimate dollar values of each industry group.

- Glass Magazine and GlassFact.com. These sources provide information regarding the total amount of glass manufactured nationally and the percentage of total glass used in the nonresidential building market.

- Ecotope. Ecotope research is used to provide information specific to the Pacific Northwest market. 
- Industry data from CBECS, F.W. Dodge, Freedonia, and U.S. Industry \& Trade Outline are also reviewed when gathering industry statistics.

This report includes estimates of volume flows and fenestration characteristics for each industry supply channel. These supply channels include primary glass manufacturers, glass coaters, window fabricators, specialty equipment suppliers, glazing contractors, framing suppliers, and window manufacturers. Ducker information is used to provide national and Pacific Northwest general volume estimates for shop-built and site-built fenestration. More detailed volume estimates are determined from the interviews. Ducker provides some limited information regarding fenestration characteristics; however, the majority of fenestration characteristic estimates are made using interview responses. Fenestration characteristic estimates for the Pacific Northwest are augmented with regionally specific information from Ecotype. 


\section{The Supply Side of the Market}

Many industry actors contribute to the process of providing fenestration for nonresidential buildings. The process begins with the primary glass manufacturers (PGMs) who make flat glass on a float line from sand and cullet. There are six major manufacturers, with 30 flat glass production facilities throughout the country, that produce nearly $100 \%$ of the glass going into the nonresidential market. Float lines are very capital intensive and run continuously for about 10 years after being started up. PGMs need a strong customer base to buy their product, since it is not possible to ramp production in response to demand. The float line product can include tinted or clear glass in a variety of thicknesses. PGMs can also apply a pyrolytic coating to one surface of the glass. A pyrolytic coating is applied while the glass is at a high temperature (thus the name) and is generally more durable than a sputter coating that is applied after the flat glass has been manufactured.

After the glass leaves the float line, it may be heat strengthened or tempered, sputtercoated, and fabricated into insulating glass (IG) units. Many of the PGMs perform all of these functions and ship IG units to window manufacturers or to glazing contractors at the job site. It is estimated that PGMs ship about 80 million $\mathrm{ft}^{2}$ of glazing product each year to window manufacturers. Almost all of this (90\%) is double glazed. About $5 \%$ is tinted and $80 \%$ has a sputter low-e coating. Window manufacturers make their own frames and ship a complete glazing system (a shop-built window) to the glazing contractors or retailers. These shop-built windows are only for punched opening windows, while site-built fenestration can be for punched openings, storefront, or curtain wall. ${ }^{14}$ Storefront and curtain wall manufacturers design, produce, and often fabricate framing for site-built products. The products are rarely shipped glazed, and it is common for glazing to be provided by other suppliers directly to the job site.

PGMs ship about 35 million $\mathrm{ft}^{2}$ to glazing contractors for site-built applications. IG units represent about $85 \%$ of this volume, $65 \%$ has a sputter low-e coating, and $20 \%$ has a reflective coating. However, the bulk of the PGMs' nonresidential flat glass production is

\footnotetext{
${ }^{14}$ A small percentage of shop-built windows are classified as storefront windows.
} 
shipped to independent fabricators (517 million $\mathrm{ft}^{2}$ ) and independent coaters (122 million $\left.\mathrm{ft}^{2}\right)$.

Independent coaters buy flat glass from PGMs, temper or heat strengthen the glass, apply reflective or sputter low-e coatings, and fabricate the glass into IG units. Almost all of their glazing is shipped directly to glazing contractors for site-built fenestration. A very small amount of their output is shipped to manufacturers of shop-built windows. About $70 \%$ of their output is IG units. All of the units they ship are coated (not including spandrel glass). About $35 \%$ have low-e coatings and $55 \%$ have reflective coatings. The final $10 \%$ accounts for spandrel glass (non-vision glass).

Independent fabricators do not have the technology to apply coatings to glass themselves, but some of the glass they buy from PGMs is coated. Fabricators tend to stock only a few types of glass, generally those that are in high demand. It is very difficult to obtain specialized coatings from independent fabricators. This supply channel has the largest barriers to energy efficiency technologies and presents the greatest opportunities for energy savings. 
Figure 1 - Supply-

Side Market Flow

Manufacturing

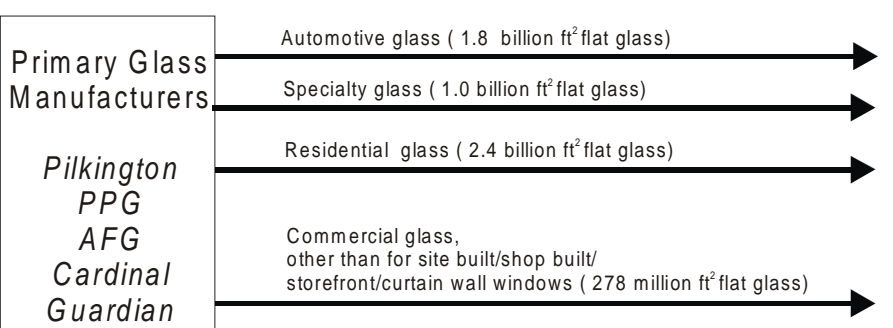

storefront/curtain wall windows ( 278 million $\mathrm{ft}^{2}$ flat glass)
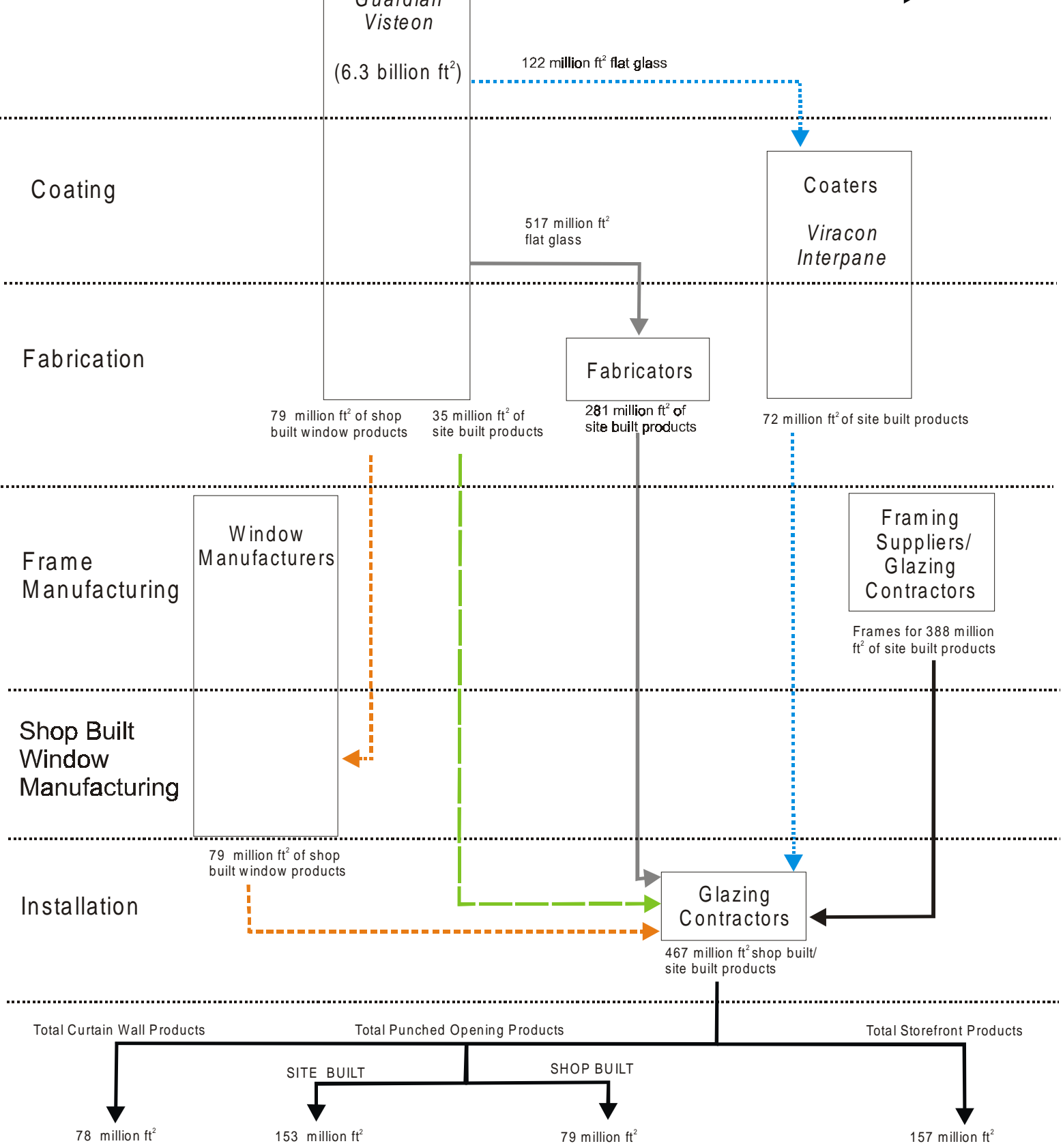

Total Storefront Products

NOTE: The term "flat glass" refers to single panes of glass.

The term "products" refers to final glazing products. 


\begin{tabular}{|c|c|c|c|}
\hline \multirow{8}{*}{$\begin{array}{l}\text { Table } 1 \text { - Total } \\
\text { Annual Flat Glass } \\
\text { Production }\end{array}$} & & Percentage & $\begin{array}{c}\text { Amount } \\
\text { (millions } \mathrm{ft}^{2} \text { flat glass) }\end{array}$ \\
\hline & Total Flat Glass Produced Annually & $100 \%$ & 6,322 \\
\hline & All PGM Glass Used for Automotive Applications & $28 \%$ & 1,770 \\
\hline & All PGM Glass Used for Specialty Applications & $16 \%$ & 1,012 \\
\hline & All PGM Glass Used for Residential Applications & $38 \%$ & 2,402 \\
\hline & $\begin{array}{l}\text { All PGM Glass Used for Nonresidential Curtain } \\
\text { Wall/Storefront/Punched Opening Windows (shipped } \\
\text { unfabricated) }\end{array}$ & $10 \%$ & 639 \\
\hline & $\begin{array}{l}\text { All PGM Glass Used for Nonresidential Curtain } \\
\text { Wall/Storefront/Punched Opening Windows (shipped } \\
\text { fabricated) }\end{array}$ & $3 \%$ & 221 \\
\hline & $\begin{array}{l}\text { All PGM Glass Used for Other Nonresidential } \\
\text { Applications }\end{array}$ & $4 \%$ & 278 \\
\hline
\end{tabular}

Table 2 - PGM

Output of Nonresidential Fenestration (millions of $\mathrm{ft}^{2}$ )

\begin{tabular}{|c|c|c|c|c|c|c|c|c|c|c|c|c|}
\hline \multirow[b]{2}{*}{ Flow } & \multirow[b]{2}{*}{ 氶 } & \multicolumn{3}{|c|}{ Type } & \multicolumn{6}{|c|}{ Glazing } & \multicolumn{2}{|c|}{ Gap } \\
\hline & & $\underline{\underline{N}}$ & $\begin{array}{l}\frac{*}{0} \\
\stackrel{5}{5} \\
\end{array}$ & $\begin{array}{l}\bar{\pi} \\
\overline{\frac{\pi}{0}} \\
\frac{\pi}{\widetilde{0}} \\
\stackrel{0}{0} \\
\end{array}$ & $\frac{\bar{\Xi}}{\frac{\Phi}{U}}$ & 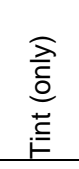 & $\begin{array}{c}0 \\
3 \\
0 \\
0 \\
\end{array}$ & 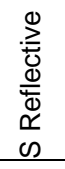 & $\begin{array}{l}0 \\
\vdots \\
0 \\
0 \\
0\end{array}$ & 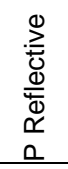 & 这 & $\begin{array}{l}\text { 들 } \\
\text { 인 }\end{array}$ \\
\hline $\begin{array}{l}\text { PGM to } \\
\text { Coaters } \\
\text { (unfabricated) }\end{array}$ & $\begin{array}{c}122 \\
\text { (flat glass) }^{*}\end{array}$ & 0 & 122 & 0 & 82 & 40 & 0 & 0 & 0 & 0 & -- & -- \\
\hline $\begin{array}{l}\text { PGM to } \\
\text { Fabricators } \\
\text { (unfabricated) }\end{array}$ & $\begin{array}{c}517 \\
\text { (flat glass) }\end{array}$ & 0 & 517 & 0 & 255 & 150 & 42 & 28 & 28 & 14 & -- & -- \\
\hline $\begin{array}{l}\text { PGM to } \\
\text { Glazing } \\
\text { Contractors }\end{array}$ & $\begin{array}{c}35 \\
\text { (product) }\end{array}$ & 29 & 4 & 2 & 6 & 8 & 14 & 7 & 0 & 0 & 27 & 2 \\
\hline $\begin{array}{l}\text { PGM to } \\
\text { Window } \\
\text { Manufacturers }\end{array}$ & $\begin{array}{c}79 \\
\text { (product) }\end{array}$ & 71 & 8 & 0 & 15 & 24 & 40 & 0 & 0 & 0 & 47 & 24 \\
\hline Total & $\begin{array}{c}753 \\
\text { (flat glass/ } \\
\text { product) }\end{array}$ & 100 & 651 & 2 & 358 & 222 & 96 & 35 & 28 & 14 & 74 & 26 \\
\hline $\begin{array}{l}\text { Percentage } \\
\text { (by category) }\end{array}$ & & $13 \%$ & $86 \%$ & $0 \%$ & $48 \%$ & $29 \%$ & $13 \%$ & $5 \%$ & $4 \%$ & $2 \%$ & $74 \%$ & $26 \%$ \\
\hline
\end{tabular}


Table 3 -

Nonresidential

Fenestration Input

to Glazing

Contractors

(millions of $\mathrm{ft}^{2}$ )

Table 4 - Total

Nonresidential

Fenestration

(millions of $\mathrm{ft}^{2}$ )

\begin{tabular}{|c|c|c|c|c|c|c|c|c|c|c|c|c|c|c|c|c|}
\hline \multirow[b]{2}{*}{ Flow } & \multirow[b]{2}{*}{$\begin{array}{l}\bar{\pi} \\
\stackrel{0}{0} \\
\end{array}$} & \multicolumn{3}{|c|}{ Type } & \multicolumn{6}{|c|}{ Glazing } & \multicolumn{2}{|c|}{ Gap } & \multicolumn{4}{|c|}{ Frame } \\
\hline & & $\underline{0}$ & $\begin{array}{l}\frac{*}{0} \\
\stackrel{0}{0} \\
\text { के }\end{array}$ & $\begin{array}{l}\bar{\pi} \\
\overline{\frac{\pi}{0}} \\
\frac{\tilde{\pi}}{\pi} \\
\text { के }\end{array}$ & $\begin{array}{l}\overline{\mathbb{J}} \\
\frac{\mathbb{U}}{U}\end{array}$ & 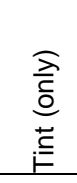 & $\begin{array}{l}0 \\
3 \\
0 \\
0 \\
\end{array}$ & 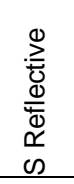 & $\begin{array}{l}0 \\
\sum_{0}^{1} \\
0 \\
a \\
\end{array}$ & 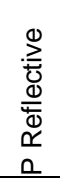 & 这 & 엄 & 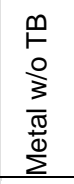 & $\begin{array}{l}\frac{m}{n} \\
\frac{3}{3} \\
\frac{\pi}{\infty} \\
\sum\end{array}$ & $\begin{array}{l}8 \\
3 \\
\end{array}$ & $\stackrel{\grave{z}}{\sum}$ \\
\hline $\begin{array}{l}\text { PGM to } \\
\text { Glazing } \\
\text { Contractors }\end{array}$ & $\begin{array}{c}35 \\
\text { (product) }\end{array}$ & 29 & 4 & 2 & 6 & 8 & 14 & 7 & 0 & 0 & 27 & 2 & -- & -- & -- & -- \\
\hline $\begin{array}{l}\text { Window } \\
\text { Manufacturers } \\
\text { to Glazing } \\
\text { Contractors }\end{array}$ & $\begin{array}{c}79 \\
\text { (product) }\end{array}$ & 71 & 8 & 0 & 15 & 24 & 40 & 0 & 0 & 0 & 47 & 24 & 0 & 31 & 28 & 20 \\
\hline $\begin{array}{l}\text { Frame } \\
\text { Suppliers to } \\
\text { Glazing } \\
\text { Contractors }\end{array}$ & -- & -- & -- & -- & -- & -- & -- & -- & -- & -- & -- & -- & 115 & 268 & 3 & 2 \\
\hline $\begin{array}{l}\text { Coaters to } \\
\text { Glazing } \\
\text { Contractors }\end{array}$ & $\begin{array}{c}72 \\
\text { (product) }\end{array}$ & 51 & 15 & 6 & 0 & 22 & 25 & 25 & 0 & 0 & 49 & 2 & -- & -- & -- & -- \\
\hline $\begin{array}{l}\text { Fabricators to } \\
\text { Glazing } \\
\text { Contractors }\end{array}$ & $\begin{array}{c}281 \\
\text { (product) }\end{array}$ & 235 & 39 & 7 & 130 & 65 & 22 & 19 & 26 & 19 & 218 & 17 & -- & -- & -- & -- \\
\hline Total & $\begin{array}{c}467 \\
\text { (product) }\end{array}$ & 386 & 66 & 15 & 151 & 119 & 101 & 51 & 26 & 19 & 341 & 45 & 115 & 299 & 31 & 22 \\
\hline $\begin{array}{l}\text { Percentage } \\
\text { (by category) }\end{array}$ & & $83 \%$ & $14 \%$ & $3 \%$ & $32 \%$ & $25 \%$ & $22 \%$ & $11 \%$ & $6 \%$ & $4 \%$ & $88 \%$ & $12 \%$ & $25 \%$ & $64 \%$ & $7 \%$ & $5 \%$ \\
\hline
\end{tabular}

\begin{tabular}{|c|c|c|c|c|c|c|c|c|c|c|c|c|c|c|c|c|}
\hline \multirow[b]{2}{*}{ Flow } & \multirow[b]{2}{*}{ 흉 } & \multicolumn{3}{|c|}{ Type } & \multicolumn{6}{|c|}{ Glazing } & \multicolumn{2}{|c|}{ Gap } & \multicolumn{4}{|c|}{ Frame } \\
\hline & & $\underline{\underline{N}}$ & $\begin{array}{l}{ }^{*} \\
\frac{0}{0} \\
\cdot \bar{c} \\
\end{array}$ & $\begin{array}{l}\overline{\widetilde{\pi}} \\
\frac{\overline{0}}{\overline{0}} \\
\frac{0}{0} \\
\text { की }\end{array}$ & $\begin{array}{l}\frac{\bar{\Phi}}{U} \\
\frac{\mathbb{U}}{0}\end{array}$ & 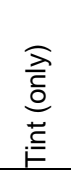 & $\begin{array}{l}0 \\
\sum_{0}^{1} \\
\infty \\
\infty\end{array}$ & 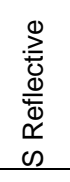 & $\begin{array}{l}0 \\
\sum_{0}^{1} \\
a \\
a\end{array}$ & 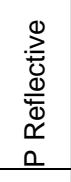 & 享 & 产 & 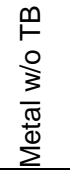 & 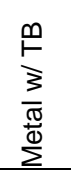 & $\begin{array}{l}8 \\
\vdots \\
3\end{array}$ & $\stackrel{\grave{\nexists}}{\sum}$ \\
\hline $\begin{array}{l}\text { Total Site-Built } \\
\text { Punched Opening } \\
\text { Products }\end{array}$ & 153 & 138 & 15 & 0 & 18 & 48 & 38 & 26 & 15 & 8 & 125 & 13 & 14 & 135 & 2 & 2 \\
\hline $\begin{array}{l}\text { Total Site-Built } \\
\text { Curtain Wall } \\
\text { Products }\end{array}$ & 78 & 59 & 4 & 15 & 4 & 21 & 15 & 22 & 8 & 8 & 55 & 4 & 16 & 62 & 0 & 0 \\
\hline $\begin{array}{l}\text { Total Site-Built } \\
\text { Storefront Products }\end{array}$ & 157 & 118 & 39 & 0 & 111 & 29 & 8 & 3 & 3 & 3 & 114 & 4 & 85 & 71 & 1 & 0 \\
\hline $\begin{array}{l}\text { Total Shop-Built } \\
\text { Punched Opening } \\
\text { Products }\end{array}$ & 79 & 71 & 8 & 0 & 18 & 21 & 40 & 0 & 0 & 0 & 47 & 24 & 0 & 31 & 28 & 20 \\
\hline Total Products & 467 & 386 & 66 & 15 & 151 & 119 & 101 & 51 & 26 & 19 & 341 & 45 & 115 & 299 & 31 & 22 \\
\hline $\begin{array}{l}\text { Percentage } \\
\text { (by category) }\end{array}$ & & $83 \%$ & $14 \%$ & $3 \%$ & $32 \%$ & $25 \%$ & $22 \%$ & $11 \%$ & $6 \%$ & $4 \%$ & $88 \%$ & $12 \%$ & $25 \%$ & $64 \%$ & $7 \%$ & $5 \%$ \\
\hline
\end{tabular}




\section{Primary Glass Manufacturers}

There are six PGMs that manufacture sheet glass from sand and cullet. The six PGMs have different business strategies and focus on different glazing technologies. All six of the PGMs tint glass, though some offer a broader spectrum of colors than the others. In general, they can be grouped into two different categories:

- The first group (three PGMs) produces a relatively large amount of glass. They apply pyrolytic coatings to some of their glass during the manufacturing process and ship $100 \%$ of their glass in cut-to-size sheets (not IG units). Their construction glass market is about $50 \%$ nonresidential and $50 \%$ residential. With the rise in popularity of sputter coatings, two out of the three PGMs have invested in sputter coating equipment and sputter coat some of their glass after the glass has left the float line and has been cut to size. The production of sputter-coated glass is increasing and is expected to further increase, while the volume of pyrolytic-coated glass has remained fairly static. Overall, low-e coatings are a fairly small portion of their production; only about $10 \%-15 \%$ of their shipped glass has a pyrolytic or sputter low-e coating.

- The second group (two PGMs) has invested heavily in low-e coating technology and focuses on the sputter-coated glass market. They do not manufacturer glass with pyrolytic coatings. One of these PGMs fabricates all of their glass into IG units on-site and ships the majority to window manufacturers. Nonresidential fenestration is only about $10 \%$ of this company's construction market. Glass from the other PGM is either sent to other fabricators or made into an IG unit and shipped directly to the job site. The second company produces limited shades of tinted glass and will purchase tinted glass from other PGMs. Nonresidential is a significant, but not large, portion of this company's market.

The sixth PGM produces less glass for the building market than the others and fits into neither of the above categories. They only produce clear or tinted glass, and all the glass they produce is shipped in sheets to fabricators or other PGMs.

\section{Coaters}

Three companies, other than the PGMs, are involved with applying sputter coatings to glass. They receive glass from the PGMs and do not manufacture any glass themselves. 
Two of these companies have similar business models and specialize in sputter coatings. Both have internal research and development groups focused on improving the performance of their sputter coatings. About half of their glazing products have a low-e sputter coating, while the other half are reflective sputter coatings. The majority of their market is curtain wall and storefront glazing for medium-to-large projects. The lead times for sputter-coated glazing can be up to 16 weeks, but this is rarely a problem because the large building projects they are involved with have construction schedules that can accommodate a longer glazing delivery timeline. Their fenestration is shipped directly to glazing contractors at the job site. Nationally, IG units make up about $70 \%$ of their product. The $30 \%$ monolithic includes laminated, spandrel, and single pane glass. About $3 \%-10 \%$ of their IG units are filled with argon. Silk-screening ceramic frit onto glass is a small, but growing, market for both companies.

The third coater is part of a fabricating firm. This fabricating firm is associated with one of the PGMs and receives the majority of their glass from that PGM. The firm has branches throughout the country, but only one site has sputter coating equipment, which primarily produces reflective (not low-e) coated glass. The other branches do IG fabrication, tempering, heat treating, and laminating. About $60 \%-70 \%$ of their market is nonresidential. All of their products are shipped directly to the job site. They have seen an increase in low-e and high performance tinted glass, but this type of glass only makes up about $10 \%$ of their market.

\section{Fabricators}

Fabricators cut, temper, heat strengthen, laminate, and fabricate IG units from standard sheets of glass that they receive from PGMs. None of the fabricators interviewed receive glass from coaters (coaters generally fabricate their own glass). Fabricators provide glazing systems for curtain walls, site-fabricated commercial windows, and storefronts. Some fabricators specialize in a particular window type. Fabricators are involved with providing spacers, which could be aluminum, stainless steel, or thermoplastic. The fabricators are not involved with the frames. Fabricators can range from single location operations that serve a small region to operations with multiple locations that serve the entire country. Local operations hold a sizable share of the fabricating market. The largest 50 fabricators hold approximately $50 \%$ of the market, while the rest is served by smaller operations.

The majority of fabricated glazing that leaves a fabricator is shipped directly to glazing contractors. Fabricators strongly influence the glass options available to glazing contractors. While glazing contractors on large projects may directly receive fabricated 
glass from a national coater or PGM, glazing contractors on small and medium projects tend to work directly with a locally situated fabricator. Fabricators do not stock all glass types available from PGMs. They are reactive to market demand and typically stock only what is commonly specified.

Most fabricators interviewed state that approximately $25 \%$ of the fenestration they supply to the nonresidential market has a low-e coating, including both sputter and pyrolytic. This, however, varies greatly by region and fabricator. A fabricator serving Florida feels low-e fenestration is $25 \%$ of their stock, while a fabricator serving the Northeast states low-e is as high as $70 \%$. One fabricator with locations throughout the country states that their fabrication sites in Tampa, Miami, Houston, and Dallas probably do not even carry any low-e glass, while their fabrication sites in New Jersey, Philadelphia, and Chicago probably stock nothing but low-e glass. All fabricators interviewed feel demand for low-e glazing is increasing.

Low-e glass is available from all the fabricators interviewed, but some are not equipped to handle sputter-coated glass and only offer pyrolytic low-e coatings. The two largest fabricators interviewed are equipped to fabricate IG units with sputter-coated glass. These two fabricators have also invested in the extra equipment necessary to temper post-temperable, low-e coated glass.

Most of the fenestration these fabricators put into the market are IG units, and the use of monolithic glass is decreasing. One fabricator, however, states that $30 \%$ of their fenestration is monolithic. The monolithic fenestration is primarily used for storefront/strip mall applications. Another fabricator states that $10 \%$ of their fenestration is uncoated IG units. This glass primarily goes to lower-end, strip-mall type buildings.

Fabricators rarely use argon fill ( $0 \%-15 \%$ of the time), and many of them question its ability to remain in the unit for the lifetime of the glazing.

\section{Specialty Equipment Suppliers}

The process of applying pyrolytic or sputter coatings is complex and requires specialized technology. A group of companies provide the equipment and technology to support these operations.

Some specialty equipment suppliers provide sputter coating equipment to PGMs and coaters. They have the capacity to build about three large machines per year, which range in cost from $\$ 10$ to $\$ 18$ million. Each machine can coat a load of glass every 30 seconds. Maximum glass dimensions are 144 in. $x 100$ in. in the U.S., and 126 in. x 236 
in. in Europe. This results in about 10 million $\mathrm{ft}^{2}$ to 50 million $\mathrm{ft}^{2}$ of glass per year per machine, when operating continuously. The coating rate depends on the number of cathodes in the machine. Edge deletion and handling concerns are not common complaints by their clients. Improvements underway include increased productivity (deposition speed) and increased product quality (uniformity of the color, tightening of color variation).

Germany and other European countries went though widespread regulatory changes in the mid-1990s that created a surge in demand for coatings. Equipment manufacturers had no problem providing equipment to meet this surge. Even though sputter coatings are gaining popularity in the U.S., there is not a large increase in equipment requests. This may be related to the weak economy and the large investment required.

Other specialty suppliers provide chemistry technology to manufacturers of pyrolytic coatings. They have no competition other than the research divisions of their customers. One firm argues that even though the architectural trend is toward clear glass, there are times when the lower visible light transmittance (VLT) from a pyrolytic coating is adequate or desired. They are working towards designing low solar gain pyrolytic coatings that provide better visible light transmission without compromising the solar heat gain coefficient (SHGC).

\section{Glazing Contractors}

Glazing contractors install both shop-built and site-built fenestration in nonresidential buildings. They are involved with curtain wall, storefront, and punched opening windows, but many contractors specialize in a certain fenestration type. Glazing contractors generally procure glass from local fabricators, but many also receive glass directly from coaters or PGMs on larger projects. Some of the larger glazing contractors receive glass directly from PGMs. Large national glazing contractors hold a significant share of this market. The top 50 glazing contractors hold approximately $80 \%$ of the glazing contracting market.

Some of the glazing contractors interviewed obtain frames from a framing supplier. Other glazing contractors interviewed design and manufacture their own aluminum frames. These companies are often involved with custom design work. Both methods of obtaining frames can be found in large and small contract glazing companies. Glazing systems can be either pre-assembled or assembled at the job site. The pre-assembled method is called a unitized approach and is used for repetitive curtain wall systems or projects on a 
tight schedule. The unitized approach is commonly used in the Pacific Northwest because the high frequency of rain makes on-site assembly less desirable.

Many glazing contractors interviewed state that they are not involved in the selection process of fenestration systems. They simply comply with the specifications given to them by the architect. Other glazing contractors feel they play a larger role. They state that architects are concerned with the look of the glass, and it is up to the glazing contractors to match the look the architect desires with acceptable performance and an affordable price.

Glazing contractors want to use products that are locally available, and the type of systems they install are dependent on what is available in a specific region. For example, thermally broken aluminum framing is commonly manufactured in the Pacific Northwest and is the standard framing system in that region. Glazing contractors seem wary of the long lead times associated with supplying glazing systems that cannot be obtained locally. Long lead times (up to 16 weeks) may not be an issue for a large curtain wall building, but can adversely affect a small storefront/retail project.

All the glazing contractors interviewed feel they work on medium- to high-end projects and generally install high performance products. They point to projects such as strip malls, retail, and fast food restaurants as projects where low-cost glass is used. The California glazing contractors interviewed also state that monolithic glass and clear IG units are often installed in California projects.

\section{Framing Suppliers}

Glazing contractors that do not manufacture their own frames will obtain frames from a framing supplier. Framing suppliers manufacture metal framing systems for curtain walls, overhead glazing, and punched openings. Storefront frames are also supplied, but to a lesser extent. Some suppliers specialize in a specific product type. Framing suppliers include approximately five large national firms and numerous smaller companies that serve specific regions. Some of the suppliers are only involved with manufacturing the frames, which they send directly to glazing contractors for installation. Other framing suppliers obtain glass from local fabricators, national coaters, or directly from PGMs, and fabricate complete fenestration systems. The framing suppliers involved with fabrication also cut and temper some of the glass they receive. If sputter-coated glass is specified, they will order the glass pre-cut and tempered from a national coater or PGM. Both the glazed and unglazed framing systems are sold to glazing contractors for installation, though framing suppliers can be involved with managing the installation. 
The framing suppliers interviewed state that thermally broken frames are used on all projects that are not in California or the South. The glazing contractors interviewed, however, feel that thermally broken frames are only sometimes used on projects outside of California and the South. All the interviewees agree that projects in California or the South very rarely use thermally broken frames. The national average of thermally broken frame use is about $66 \%$.

\section{Window Manufacturers}

Window manufactures provide completely fabricated and framed fenestration systems. They primarily supply punched opening windows and are involved with nonresidential buildings that have this type of fenestration design, such as institutional buildings, academic buildings, hotels, and high-rise condominiums. They are also involved in replacement fenestration for historically significant buildings. The majority of their market is residential projects. Nonresidential projects only make up $8 \%-20 \%$ of the their market.

Window manufacturers receive glass directly from PGMs, some of which is prefabricated and some of which they fabricate on-site. Most manufacture their own frames. Frames from window manufacturers can be aluminum, wood, vinyl, or wood with an aluminum or fiberglass cladding. Each window manufacturer specializes in a particular combination of these frame types.

Since window manufacturers receive a significant portion of their glazing prefabricated from the PGMs, IG units with a low-e coating and argon fill are very common. Some window manufacturers provide as much as $85 \%$ of their product with low-e coatings. Argon fill is used in most fenestration with low-e coatings because the PGMs provide the IG units that way.

One window manufacturer states that occasionally low-e coatings will be removed from a project, but feels this is rare. The manufacturer also states that occasionally architects working on historic renovations will want clear IG because they are concerned with the aesthetic look of a low-e coating, but also feels that this is fairly rare. 


\section{The Demand Side of the Market}

Choosing fenestration products in nonresidential buildings is a collaborative effort that involves architects, owners, mechanical engineers, and glazing contractors. Each is motivated by different concerns. Architects are primarily motivated by aesthetics, owners by cost, mechanical engineers by performance, and glazing contractors by product availability. Architects have the greatest influence on the choice of products and, consequently, aesthetic trends have a significant effect on the glazing market (see Industry Trends).

\section{Architects}

Architectural firms receive technical information directly from PGMs, though this is more common with larger firms. Some architects are proponents of energy-efficient products and view fenestration as a building system. These architects state that they are getting more involved with analyzing the performance levels of their fenestration options. Most other architects only specify what is required by building energy codes. In general, architects feel they will make an aesthetic choice within a range of product performance that meets code.

Most architects feel initial cost limits their choices and is the sole reason high performance glazing is not specified into more nonresidential buildings. At the same time, architects consider high performance systems relatively cost-effective and one of the last energy-efficient building features to be completely removed from a design. Architects feel that the owner's influence rarely changes the glazing selection, even though owners are generally looking for the lowest cost.

The location and area of fenestration in a building seems to be solely the architect's decision. Input from the mechanical engineer and the glazing contractor will change the product type, but not the product size. Most energy codes require more efficient fenestration as the fenestration area increases. Energy codes have multiple compliance options. While the prescriptive option will limit the window-wall ratio (WWR), larger glazing areas can be achieved through use of trade-off options.

Some of the architects interviewed state that when they present the cost-effectiveness of various glazing options to their clients, the option with the lowest initial cost is simply 
chosen. Cost-effective information is more commonly requested on public projects because it is often required. Analyzing the cost-effectiveness of product designs is much less frequently done for private projects.

All architects interviewed are involved in medium- to high-end work and feel higher performing fenestration is commonly specified and rarely questioned. However, the architects' definition of high performing fenestration is limited by their knowledge of glazing technologies and does not necessarily categorize the glazing in a project in the same way as a more-informed decision maker. For example, many architects do not understand all the nuances of low-e: some do not know that there are significant performance differences between sputter and pyrolytic coatings, both in terms of heat flow, but also daylight transmittance. Others presume that all thermal breaks are the same: they are not aware that "thermal break" is a generic term that includes plastic isolators, other thermal improvements, and skip-debridging, as well as true pour-anddebridge thermal breaks. Many are not aware of the range of low-conductance spacers available in the market.

\section{Owners/Developers}

Developers are primarily driven by cost and aesthetics. They want to minimize initial cost and ensure that their building is attractive to potential tenants. A building is primarily seen as an investment, and any deviation from conventional practice could be a financial loss. The benefits from fenestration technologies need to be clear and substantial to justify increased initial costs. Even a nominal increase may be rejected if the benefits are not great enough. Low-e coatings, for example, are often left off of IG units when the fenestration orientation does not maximize the benefit of a low-e coating or the energy reduction gained is not enough to downsize the HVAC system.

Developers of office buildings often want their building to be aesthetically similar to the other buildings in the immediate surroundings. A building that stands out in an undesirable way may dissuade potential tenants. This deters developers from using technologies that may create a different look than commonly specified products.

Developers of retail buildings want clear glass. Marketing groups feel that clear glass creates a more inviting retail atmosphere by allowing customers to look into a building from the outside. Visibility into the building from the outside is also important for security concerns. Developers are wary of adding tinting or coating technology that may reduce the clarity of the glazing. Furthermore, developers feel the energy savings and comfort gained from high performance fenestration has minimal benefit to a retail store: retail 
stores generally have short life spans and customers rarely stay in a store long enough to be affected by an uncomfortable environment. This concern over glare is partially caused by a mistaken assumption that low-e means tinted or reflective. "Clear" low-e coatings have a light transmission that is only slightly less than clear glass without low-e coatings. Seattle's largest downtown retail complex (Westlake Center) was built in the late 1980s and has clear low-e coatings throughout. There are three floors of storefront fenestration, all of which can be easily seen through from the street below. The Washington State Energy Code as of July 2001 requires that all storefront fenestration have low-e coatings.

\section{Mechanical Engineers}

Mechanical engineers analyze glazing performance and generally have little influence over the glazing type chosen for a project. Their role is to ensure that architects' glazing choices perform adequately with the chosen HVAC system. They can also be involved with verifying that the fenestration system meets code. Mechanical engineers can be wary of downsizing the HVAC system when high performance materials are used to reduce the energy loads. HVAC systems for nonresidential buildings are large and complex, and specifications often rely on HVAC sizes used in previous projects. Larger architecture firms often have an in-house engineering group, which can facilitate better communication between the architect and mechanical engineers.

\section{Electrical Engineers}

Electrical engineers are generally not involved with building glazing choice, and interior lighting is not an influencing factor for fenestration selection. Fenestration is rarely chosen in conjunction with a lighting system because the specific building space use often has not yet been determined at the glazing stage of a project. Developers are wary of limiting their leasing options by have a predetermined amount of interior light in the building.

\section{Glazing Contractors}

The glazing contractor informs the architect and owner how much their chosen glazing system will cost, and may possibly present less expensive alternatives. Most glazing contractors interviewed believe they are simply providing information on glazing systems specified by the architect. If the architect feels the cost is too high, the glazing contractor will provide cheaper alternatives while considering the glazing characteristics desired by 
the architect. Many of the architects interviewed, however, feel that the glazing contractors played a larger role in fenestration selection. If a fenestration type gets removed from the specification due to cost, then the glazing contractor has significant influence over the product options from which the architect will choose an alternative. Glazing contractors are concerned with long lead times on small-to-medium size projects and often use readily available glazing materials. This is not as much of an issue with large projects, since other parts of the project will always have longer lead times than the glazing. 


\section{Industry Trends}

Increased economic growth has boosted nonresidential construction in recent years.

Based on nonresidential construction activity, Ducker research estimated total

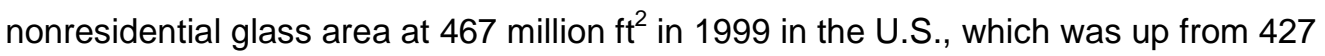
million $\mathrm{ft}^{2}$ estimated for $1998 .{ }^{15}$ Ducker forecasts that nonresidential glass area will oscillate at or above the 1999 level through $2003 .{ }^{16}$ High performance fenestration is increasingly being specified for nonresidential buildings, but there is an increased aesthetic desire within the architectural community for clearer looking glass and this has lead to the use of lighter-tinted, high performance blue and green tints. Low-e coatings have become a popular way to provide a clear looking glazing while still providing adequate performance. The increased use of IG units, due to energy codes and greater awareness of energy efficiency, has also influenced low-e use by reducing the incremental cost of adding low-e coatings. Sputter low-e coatings are gaining popularity over pyrolytic low-e coatings. One of the reasons for this shift is the higher VLTs available from sputter coatings compared to a pyrolytic coating of similar performance. The higher VLTs provide more daylighting with less heat gain. Post-temperable coatings are beginning to emerge as a way to allow fabricators to stock standard sizes of low-e coated glass.

Certain energy-efficient technologies have seen only limited growth. Three-layer glazing products with two layers of glass having a suspended film in between tend to only be used in "green" building projects. Low-conductance spacers are only manufactured by a few companies that have made the initial investment to change their spacer production process. While argon fill seems to be commonly used by window manufacturers (for shop-built punched opening windows), most interviewees are wary of argon's performance and ability to last within an IG unit.

Some energy-efficient technologies have not enjoyed market growth. Interviewees feel the use of pyrolytic coatings has remained static or has slightly declined. Most U.S. Market," April 2000. 
interviewees state that they rarely use triple glazed fenestration with three layers of glass due to weight, cost, and durability concerns.

\section{Transparent Glass}

The popularity of transparent glass is increasing the demand for low-e coatings, as designers look for products that have a low SHGC and U-factor, yet a high VLT. Almost everyone interviewed agrees that there is a strong aesthetic trend toward clearer glass. Architects want occupants to feel closer to the outdoors and for the inside of the building to be visible from the outside. There is also a desire to increase the amount of daylight entering the building. The WWR has remained stable while designers are being drawn towards clearer looking glass. Very clear low-iron glass is popular, especially in lobbies. There is an increased demand for energy-efficient fenestration technologies that allow high levels of VLT. To achieve a more transparent look while maintaining necessary solar performance, high performance tints and low-e coatings are more often used.

Conversely, the use of reflective coatings and dark tints are declining in most parts of the country and are being replaced with a low-e and light tint combinations. Medium reflective coatings are still popular in the South because of the strong direct sunlight in that region. Some coaters are working to design reflective coatings with higher levels of VLT.

Desire for greater visible light transmission in fenestration products has also encouraged the use of silk-screened glass. Ceramic frits silk-screened onto glass are replacing tinted glass in many applications, again because it is possible to maintain a high VLT and reduce glare. Recent examples of ceramic frit use include San Francisco International Airport and the Los Angeles Convention Center. Silk-screened glass can "fadeout" from the top of the fenestration to the bottom, reducing glare. It can also be customized, which appeals to architects.

Incorporating the use of overhangs in building design is also increasing. This is especially true in California.

Some interviewees emphasize that this is an aesthetic trend that may change in the future. Some of the PGMs feel glare problems might produce a backlash towards highly visible, light transmitting glass. Glare problems can result in closed blinds, which remove all daylight and view from the building. 


\section{Greater Use of Punched Opening Windows}

Ducker Research estimated that in $1999,50 \%$ of the fenestration going in commercial buildings was punched opening. ${ }^{17}$ Traditionally, storefront/curtain wall glazing systems hold a greater percentage of this market. Glazing contractors note seeing a shift in glass systems; strip windows and punched opening windows are taking the place of curtain wall/window wall/storefront systems. Industry leaders identify a few possible reasons for this trend:

- Contractor insurance rates are higher for site-built fenestration installations than manufactured window installations. This may be due to site-built construction being a more dangerous process. Site-built fenestration also has higher failure rates, increasing the building insurance rates for buildings with curtain wall construction.

- It is difficult to find the qualified labor necessary for site-built installations and this may be pushing buildings toward more manufactured windows.

- There is an architectural trend toward low-rise nonresidential buildings having a more residential look. This means more punched opening windows.

- Replacement of fenestration for older buildings. Older buildings have more punched opening windows and this sector of the market is growing.

Shop-built punched opening windows are primarily marketed to residential buildings. Nonresidential is currently a small part of the window manufacturers' market, though they express an interest to increase market share. An increase in the use of shop-built, punched opening windows could have a positive effect on energy efficiency. Energyefficient technologies, such as low-e coatings and argon fill, are much more commonly used in shop-built punched opening windows compared to any type of site-built product.

\section{Low-e Coatings}

Everyone interviewed states that the use of low-e coatings is rapidly increasing in the nonresidential market. Glazing contractors feel a significant portion of the glass they 17 Ducker Research Company. "The Distribution of Residential Doors and Windows in the 1999
U.S. Market." April 2000. 
install already have low-e coatings. Most architects interviewed feel low-e coated products are the most common type of glazing currently specified. They state that the specification of low-e is rarely questioned and is considered one of the most costeffective, energy-efficient features that can be added to a building. Ducker reports that low-e products are $14 \%$ of the nonresidential market. ${ }^{18}$ Interviewees in most regions of the country feel this number is low, stating that low-e has become quite conventional for their projects.

Low-e coatings can be either pyrolytic (hard coat) or sputter (soft coat). Pyrolytic coatings are applied during manufacturing, after the glass leaves the tin bath. Pyrolytic coatings are promoted as being easier to fabricate: they come off the float line already coated; they can be touched; they do not require edge deletion; and they can be tempered or laminated after the low-e coating is applied. Pyrolytic promoters also state that the SHGC performance of a hard coat in combination with a good tint is competitive with soft coat performance.

Sputter coatings are generally applied at the time of fabrication. This process is done by PGMs and independent coaters. There are no independent fabricators with sputter coating equipment. Sputter coatings are promoted as performing better than pyrolytic coatings because they can reduce SHGC while maintaining good VLT. Sputter promoters resist the notion that soft coats are difficult to handle, saying that newer soft coats are becoming easier to handle and adjustments to the fabrication process are quick and easy. One PGM was able to adjust its shipping and warehousing protocol in less than a month from when they first began using sputter-coated glass.

The use of sputter coatings limits the possible channels of fabrication. Sputter coatings must be applied to fresh glass (less than a month after production). Some interviewees say there are no issues with laminating sputter-coated glass, while others say only some sputter coatings can be laminated. Edge deletion is required because the silver in the sputter coating corrodes. Edge deletion slows the fabrication process and aesthetically changes the fenestration edge. Sputter coaters are working to prevent the corrosion, and thereby eliminate the need for edge deletion, by adding a silicon coating over the silver.

Traditionally, sputter-coated glass cannot be post tempered, requiring that the glass be cut and tempered before the sputter coating is applied. This prevents local fabricators from stocking sputter-coated glass and creates long lead times (up to 16 weeks) for 
sputter-coated glass to reach a job site. Newer varieties of low-e coatings can be post tempered, although it is a more delicate tempering process. Post-temperable sputter coatings have not yet achieved the same level of performance as conventional sputter coatings.

Low-e coating is a standard feature for most punched opening windows from window manufacturers. The majority of the window manufacturers' market is residential, and lowe coatings have been common in the residential market for years.

The Southern market seems to be the one region where low-e coatings have not gained significant popularity. Architects and glazing contractors state that low-e does not effectively block the intense direct sun in the Southern region. Reflective coatings, placed on monolithic glass or an IG unit, are much more common in these areas.

Glazing contractors in California state that low-e coatings were not very popular in the past because most of the California market was monolithic glass. Sputter coatings are delicate and must be placed in an IG unit to protect them from humidity and contact. The glazing contractors feel that since the new California energy codes are requiring IG units, low-e coatings will become ubiquitous in the California market. The extra cost to add a low-e coating to an IG unit is considered minimal by the glazing contractors.

Interviewees from the Pacific Northwest state that low-e coatings are almost always used. Retail stores are the only exception, partly because of optical concerns. However, the 2000 Washington State Energy Code requires low-e coatings on large street level fenestration. The 2001 Seattle Energy Code requires low-e coatings on fenestration products in all buildings.

Interviewees state that low-e sputter coatings add about $\$ 1.00 / \mathrm{ft}^{2}$ to $\$ 2.00 / \mathrm{ft}^{2}$ to the glazing cost. Pyrolytic-coated products are generally about 15\% to $25 \%$ less expensive than sputter-coated products.

\section{Post-Temperable Coatings}

Traditionally, glass has to be cut, tempered, then coated. Post-temperable low-e coatings allow glass to be cut and tempered at fabrication sites closer to the job site, which reduces the traditional 10 to 16 week lead time associated with sputter-coated glass. Post-temperable coatings allow the coater to stock many sizes of glass, which maximizes productivity. One coater states increasing productivity is a big concern because they currently cannot meet demand. Post-temperable coatings are expected to gain market share of small and medium nonresidential jobs. 
Post-temperable coatings are available, but have not yet gained much market share because the initial cost of enhancing the tempering line (more tempering equipment is needed) has prevented fabricators from making the shift. Tempering this type of glass also slows a tempering line, which results in a lower yield to the fabricators. There is a future trend (estimated to be 10-20 years away because of the high initial cost) to temper with convection heating. This would speed the process of tempering sputter-coated glass. Currently aspirators are being added to radiant tempering machines to augment the radiation heating with convection heating. This intermittent step is improving tempering rates.

Post-temperable coatings could potentially take market share away from independent coaters. Post-temperable coatings, however, seem to be targeting smaller construction products and local fabrication shops, since post-temperable coatings allow tempering and fabrication to occur on the local level. This streamlines the shipping process, but small local fabricators will not be able to handle very large jobs, which is the large coaters' primary market.

Performance and selection of post-temperable coatings is not yet comparable to traditional low-e sputter coatings. One coater states this is a heavy area of research and development within their company. Expanded post-temperable low-e coating lines can be expected in the near future.

\section{Thermally Broken and Thermally Improved Frames}

Thermally broken refers to frames that are split into interior and exterior sections and have a less conductive material connecting them. Thermally broken frames have been on the market for a long time. There are four common types of thermally broken frames:

- Pour and debridge polyurethane. This system is used for punched opening windows, but not curtain walls due to structural limitations.

- Strut systems. This system has a continuous polymer piece inserted into the aluminum. This is also used for windows. It is more expensive than the pour and debridge design, but gives the option for different finishes on the inside and outside.

- Pressure bar systems with low conductance spacers and fasteners. This system is used for curtain walls and is considered a more expensive design.

- Non-continuous polymer clips. This system is used for storefront fenestration and strip windows that are not operable. The glass needs to be installed from the outside, 
which limits this design to low-rise buildings. Non-continuous polymer clips are considered a cheaper alternative to the pour and debridge design.

Thermally improved frames are also used. This system is cheaper and structurally stronger than a thermally broken system. They do not perform as well as thermally broken framing, but they are about $20 \%$ less expensive. Thermally improved framing is gaining popularity in the northern part of the U.S.

Thermally broken frames (pour and debridge) are not used in curtain wall design for structural reasons. When thermally broken curtain walls include operable fenestration, these operable units may be thermally broken using the pour and debridge method even though the curtain wall framing uses another method of providing a thermal barrier.

The use of thermally broken frames is distinctively divided by geographic region. The glazing contractors and fabricators interviewed feel thermally broken frames are almost always used in northern regions. This is partly due to the ability of thermally broken frames to reduce condensation. Interviewees stated that condensation reduction is a significant concern to building owners and one of the bigger selling points for thermally broken frames. Most of the interviewees in the northern regions state they only use thermally broken or thermal improved frames. They also feel that thermally broken/improved frames are $60 \%-80 \%$ of the overall nonresidential market, and the market share is increasing. Some of the large architecture firms interviewed state that they use thermally broken or thermally improved frames on most of their projects.

Thermally broken aluminum frames are almost never specified in California and the southern regions. Glazing contractors state that thermally broken frames are not considered beneficial in these climates.

One glazing contractor in the Pacific Northwest that manufacturers thermally broken frames feels the high initial cost of converting the frame manufacturing process to thermally broken production is holding back this market conversion. In this manufacturer's opinion, once the initial cost of conversion is made, the production costs of thermally broken and unbroken frames should be fairly similar.

Interviewees that manufacture thermally broken frames state that the frames have no cost premium because it is the only type of frame they sell. Large framing suppliers were vague about the cost of thermally broken frames. One national glazing contractor states that thermally improved frames carry a premium of $\$ 0.25 / \mathrm{ft}^{2}$. 


\section{Vinyl Frames}

While the glazing contractors interviewed state they do not use vinyl frames, one industry expert says that vinyl frames are beginning to be used in more nonresidential buildings that are less than eight stories. This excludes the ground floor, which is traditionally a storefront/curtain wall. Storefront/curtain wall is rarely, if ever, done with vinyl. The wind load at stories greater than eight often precludes the use of non-reinforced vinyl.

\section{IG Units}

There has been a trend towards IG units in regions that traditionally used monolithic glass. In California, the ratio of monolithic to IG was $2: 1$ in 1989 . That ratio had flipped by 1999 and is expected to increase more rapidly as new codes are enforced.

\section{Triple Pane Fenestrations}

The term triple pane fenestration refers to a fenestration product with three panes of glass or a double pane IG unit with a suspended interior film, usually polyester. Ducker reports triple pane glazing at only $2 \%$ of the nonresidential market. ${ }^{19}$ Interviewees agree that triple pane fenestration is rarely used and see no reason why they would increase in the future, though the products with suspended films are being used in some "green" buildings.

The added weight and extra sealant surface area seem to be preventing the market growth of triple pane products made with three layers of glass. Along with the increased cost of materials, triple pane products cost more to install because the heavier weight requires more manpower or machinery during the installation process. Failure of the sealant is a big concern, and having two extra seals doubles the chance of failure. Threelayer products having two layers of glass with a suspended film do not have the increased weight problem associated with three panes of glass, but there is concern over how the look of a suspended film will hold up over time (may start to sag). Suspended films are also more difficult to assemble and handle during fabrication. 
Architects feel that triple pane fenestration is only appropriate in very cold climates where U-factor concerns dominate fenestration design. This represents a very small percentage of nonresidential buildings in the U.S., except for Alaska. Architects also feel glass technology has advanced to a point where low-e coated, dual glazed units can perform at a level comparable to a triple glazed system. One manufacture of suspended films defends triple pane fenestration, stating they still offer the highest level of performance and that their market has remained stable. Triple pane fenestration is two to two-and-ahalf times more expensive than conventional IG units.

\section{Spacers}

Spacers are placed within an IG unit to keep the panes of glass separated at an appropriate distance. Spacers have several additional functions. They prevent the passage of water that would fog the unit. They create an insulated barrier that reduces the formation of interior condensation at the edges. They assist in providing an airtight seal for air or argon fill. They also accommodate stress induced by thermal expansion and pressure differences.

Glazing contractors and architects state that aluminum spacers are almost always used for all fenestration types except shop-built, punched opening windows supplied by window manufacturers. Aluminum's malleability makes it an easy medium to work with, but its excellent ability to conduct heat reduces the overall thermal efficiency of the glazing system.

Glazing contractors and frame suppliers cite reliability concerns as the main reason the industry has not shifted away from aluminum spacers. Interviewees state that curtain walls are meant to last much longer than typical residential (shop-built punched opening) windows. Replacing fenestration in a high-rise building is also a more costly process and a greater liability than replacing a residential (shop-built punched opening) window. These concerns make the industry wary of trying new technologies that do not have a history of proven reliability. In response to this, aluminum spacer manufacturers have been refining their products to reduce heat flow and now offer a range of variations beyond the standard aluminum spacer.

One fabricator interviewed produces spacers made from thermoplastic. Thermoplastic is a plastic material that conducts heat much less than aluminum to provide a better thermal efficiency for a glazing unit. Along with reducing heat transfer, the interviewee states that thermoplastic spacers are better at retaining argon gas. There is a $\$ 3$ million initial investment cost to manufacture spacers from thermoplastic, but labor costs are stated as 
being lower with the thermoplastic systems. There are only two companies in the U.S. that manufacture thermoplastic spacers. Thermoplastic spacers are more popular in Europe. This fabricator states that the thermoplastic spacers are sold at no cost differential to aluminum spacers.

One window manufacturer interviewed states that stainless steel is used almost exclusively for their spacers. One window manufacture states that their windows have steel spacers because they have the equipment to bend the steel. Aluminum spacers are used on certain custom products where bending the steel would be difficult.

Glazing contractors estimate a cost premium of $\$ 1.00 / \mathrm{ft}^{2}$ to switch from standard aluminum spacers to lower conducting materials and designs.

\section{Argon Fill}

Argon gas can replace the air separating the inner and outer lites in IG units. Except for shop-built punched opening windows, most of the interviewees state that argon fill is rarely used and question its performance. Interviewees state that a lack of measuring equipment also makes it hard to identify that argon is in the IG and to verify that the argon remains in the IG unit. ${ }^{20}$ Interviewees add that the filling process is inefficient and significant amounts of argon is wasted.

Argon fill is very common in punched opening windows sold by large window manufacturers who are heavily involved in the residential market. These are the same windows used for residential applications. Window manufacturers receive a significant portion of their IG units prefabricated from PGMs. Window manufacturers interviewed state that the PGMs add argon as a standard feature to IG units that have a sputter coating. Argon use is significantly lower in punched opening windows sold by window manufacturers that specialize in the commercial sector.

Argon fill seems to have greater popularity in the Pacific Northwest. While still generally rare in site-built applications, some architecture firms are commonly specifying argon and glazing contractors in the region feel argon is increasing in use.

\footnotetext{
${ }^{20}$ Currently, measuring devices are available for determining the presence of argon and other gases at a cost less than $\$ 500$.
} 
There are issues with shipping argon-filled units across regions with different atmospheric pressures. Argon fill that is equilibrated with atmospheric pressure at sea level may leak when at a higher altitude with a lower atmospheric pressure. This makes the availability of argon fill dependent on the proximity of a job site to a location where argon filling takes place.

Fabricators list a $\$ 0.25 / \mathrm{ft}^{2}$ to $\$ 0.50 / \mathrm{ft}^{2}$ premium for argon fill.

\section{Tinted Glass}

There are two kinds of tints on the market. The standard tints include bronze, gray, blue, and green. These tints all have about the same SHGC, but green and blue tints have a higher VLT. The other category is often called high performance tints. These are blue and green tints that have a similar VLT to standard blue and green tints, but have a SHGC approximately $15 \%$ lower than standard tints. Glass is tinted by PGMs during the manufacturing process. Tinted glass holds a big percentage of the market, with PGMs stating that about half of their glass is tinted. Clearer glass is a current aesthetic trend and the market has seen demand for tints shift from bronze and gray colors to blue and green, which have a higher VLT.

Glazing contractors feel $60 \%-80 \%$ of their glazing systems are tinted, and many state that high performance tints are common. Architects state a general propensity for lightcolored tints.

Some of the PGMs heavily involved in tinted glass state that their older (lower performing) tints are frequently specified and still hold a large part of their market, even though they have had high performing tints on the market for a few years. The standard tints are about half the cost of high performance tints, probably due to their large production volumes. The PGMs feel the specification of older tints has less to do with cost and more with the fact that architects just get used to specifying what they know and are resistant to change.

\section{Reflective coatings}

Reflective coatings can be pyrolytic (applied by PGMs during the manufacturing process) or sputter (applied by a coater). Both pyrolytic and sputter reflective coatings are durable enough to be placed on monolithic glass. 
Clear glass is an aesthetic trend. Interviewees agree that the shiny look is less desired and the market is moving away from highly reflective coatings. Medium reflective coatings are still popular and commonly used in the South. Architects and glazing contractors from that region feel reflective coatings are necessary to effectively block out the intense direct sun in the South. Medium reflective coatings are commonly being applied to the third surface of an IG unit, rather than the second. This reduces performance, but creates a subtler look that is more aesthetically desirable.

Reflective coatings are also commonly used on monolithic glass in California. This may change now that high performance fenestration is required by California code.

The use of reflective coatings is declining in all other parts of the country. Many architects and glazing contractors comment that reflective coatings are being replaced by low-e coatings in combination with tinted glass.

Coaters estimate a $\$ 1.00 / \mathrm{ft}^{2}$ to $\$ 2.00 / \mathrm{ft}^{2}$ premium for reflective coatings. Reflective coatings are generally in the same price range as low-e coatings, but tend to be slightly cheaper.

\section{Laminated Glass}

Laminated glass is constructed by bonding a polyvinyl butyral (PVB) plastic interlayer between two pieces of glass under heat and pressure. Once sealed, the sandwiched glass behaves as a single unit and appears transparent. Annealed, heat-strengthened, or tempered glass can be used in the production of laminated glass.

Laminated glass can increase the fenestration's energy efficiency if the PVB laminate is treated. The laminate can be tinted to absorb heat, and the laminate can be used to protect sputter coatings placed on the glass. The industry is also beginning to experiment with placing sputter coatings directly on the laminate. Aside from energy benefits, laminated glass has the advantage of reducing noise, reducing injury when broken, slowing down theft when broken, and preventing UV fading.

Two U.S. companies produce the PVB plastic interlayer for laminated glass. This laminate is sent to PGMs, coaters, and fabricators that perform lamination. The laminated glass is then sent to framing suppliers, directly to glazing contractors, or to distributors.

The market for laminated glass consists of buildings in areas with hurricane codes, as well as retail stores and banks with high security concerns. Laminated glass is 
sometimes used in high-rise buildings instead of tempered glass. This is common in hotels next to airports or other sites where noise may be an issue.

Laminated glass is a very small percentage of the overall nonresidential market, but is increasing in use. This is partly due to new hurricane codes in Florida, Texas, and the Gulf and Atlantic Coasts, which are big markets for laminated glass. Increased demand for greater security and acoustical performance is also increasing the specification of laminated glass.

The cost of laminated glass ranges from being competitively priced with an IG unit with tempered glass to being about $30 \%$ more than the IG system.

\section{Energy Efficiency Codes}

Many of the interviewees advocate the increased use of energy codes. Some parts of the country have codes that are weak or nonexistent (see Figure 4). Interviewees feel regulations raise architectural consciousness of energy-efficient products and would have a quick and significant effect on the market. Many interviewees emphasize that voluntary actions are not strong because of the higher initial cost of energy-efficient fenestration products. Codes are necessary to prevent developers, who quickly sell the buildings after completion, from building at variance from minimal standards and failing to meet accepted social goals, such as energy conservation. They feel that, if forced, architects and the nonresidential fenestration market would quickly adjust to higher standards of product performance. Interviewees cite the effective adjustment to higher levels of performance in the residential market as evidence of a successful market transformation.

Some architects state that codes drive what products they specify in buildings. The architects feel that much of the architectural community in general is not concerned with energy efficiency. Aesthetics are their primary concern and they will not specify energyefficient products unless required by code. Architects also feel the majority of clients are not sophisticated enough about fenestration options to request energy-efficient products.

Many glazing contractors and frame manufacturers feel codes are having the greatest effect on product performance. Specifically, they cite the increased regulations on solar control in California, Texas, and Massachusetts as having greatly increased the level of fenestration performance specified in these states. In general, they feel forcing the market is the only way to increase demand for glazing products with a higher initial cost.

Support for codes is unanimous, but there is concern over bogging down the system with unneeded complexity and extra paper work. Interviewees feel any guidelines or 
regulations should be streamlined as much as possible. Many of the interviewees on both the supply and demand side of the market advocate simply mandating beneficial fenestration characteristics that are readily available and easy to make universal. Suggestions include requiring all glazing to be IG units and banning the use of aluminum framing that is not thermally broken. Other interviewees feel standards should not mandate specific fenestration technologies. Rather, the overall energy efficiency performance of nonresidential buildings should be regulated. The manufacturers of hard coatings specifically raise concerns about any codes that would force the use of sputter coatings. They do not want regulations that would specifically cut pyrolytic coatings out of the market. They feel the sputter coaters could not handle such a large surge in the market if sputter low-e is required on all glazing products.

One consultant feels different performance parameters are needed for different types of nonresidential buildings. Hotels and offices have very different glazing systems, and should have different performance requirements. Requirements should be stringent, but reasonable, given the inherent qualities of each building type.

One manufacturer of high performance fenestration products wants to see codes that require a minimum level of performance, but rewards the developer/owner in some way if they go beyond that minimum. While ratings breed competition, this interviewee emphasizes that creating an incentive for very high product performance promotes innovation.

Glazing contractors in California are concerned with the enforcement of codes. Without enforcement, owners will just delete from the specifications any higher performing products specified by the architect. One California glazing contractor states the he receives specifications for fenestration products that do not comply with California energy code (Title 24) prescriptive requirements. ${ }^{21}$ Codes in Washington are being updated to make low-e coatings nearly mandatory. Currently, Seattle requires National Fenestration Rating Council (NFRC) certification for all fenestration. The stringency of Seattle's energy code has been increasing since it was first established in 1980. The initial performance requirements pushed IG units into the market. Before the 1980 code, monolithic glazing was common. This reduced the need for separate perimeter baseboard heating, a benefit that caused designers to look more closely at the performance of different fenestration systems. Seattle then adopted ASHRAE 90.1 guidelines for larger nonresidential

21 It is possible that the building still complies using the Title 24 performance method. 
fenestration. Requiring higher performance for larger openings motivated designers to specify higher performing smaller fenestration, since they were already ordering high performance fenestration onto the job site. Currently, low-e coated IG units are specified on about $80 \%$ of nonresidential projects in Seattle.

\section{ASHRAE/IESNA Standard 90.1}

Standard 90.1 is a national consensus standard co-sponsored by the American Society of Heating, Refrigerating and Air-Conditioning Engineers (ASHRAE) and the Illuminating Engineering Society of North America (IESNA). The Standard provides minimum requirements for energy-efficient design and construction of all buildings except for lowrise residential. The Standard is the result of a consensus process, meaning participants in the development and review of the Standard included professional, technical, and trade organizations; environmental organizations; equipment manufacturers; utility companies; code officials; and design professionals. There are two editions of the Standard: the 1989 edition and the 1999/2001 edition. ${ }^{22}$

The Standard is not a code, but is written in code enforceable language and is intended for adoption by national, state/province, and local code jurisdictions. The 1992 Energy Policy Act (EPAC) requires all states to adopt energy codes equivalent to the 1989 version of the Standard. It is expected that the USDOE will soon update that reference to the 2001 version of the Standard. Figure 2 shows which states currently (January 2002) have adopted the ASHRAE Standard (or equivalent).

In terms of fenestration, the Standard establishes maximum fenestration U-factor and SHGC values, specific to climate region and fenestration size. Figures 3 and 4 show the $\mathrm{U}$-factor and SHGC requirements for fenestration products throughout the country. Only SHGC requirements vary by fenestration size. The maximum SHGC values shown in Figure 4 refer to fenestration in a building that has a 0.2 to $0.3 \mathrm{WWR}$. Requirements in the U.S. range from a $1.22 \mathrm{U}$-factor and $0.25 \mathrm{SHGC}$ in the South to a $0.32 \mathrm{U}$-factor and no SHGC requirement in Northern Alaska.

22

The 1999 version was recently updated to the 2001 version. The changes between the 1999 and 2001 versions are not substantive. 
Figure 2 -

ASHRAE 90.11999 Fenestration

U-factor

Requirements

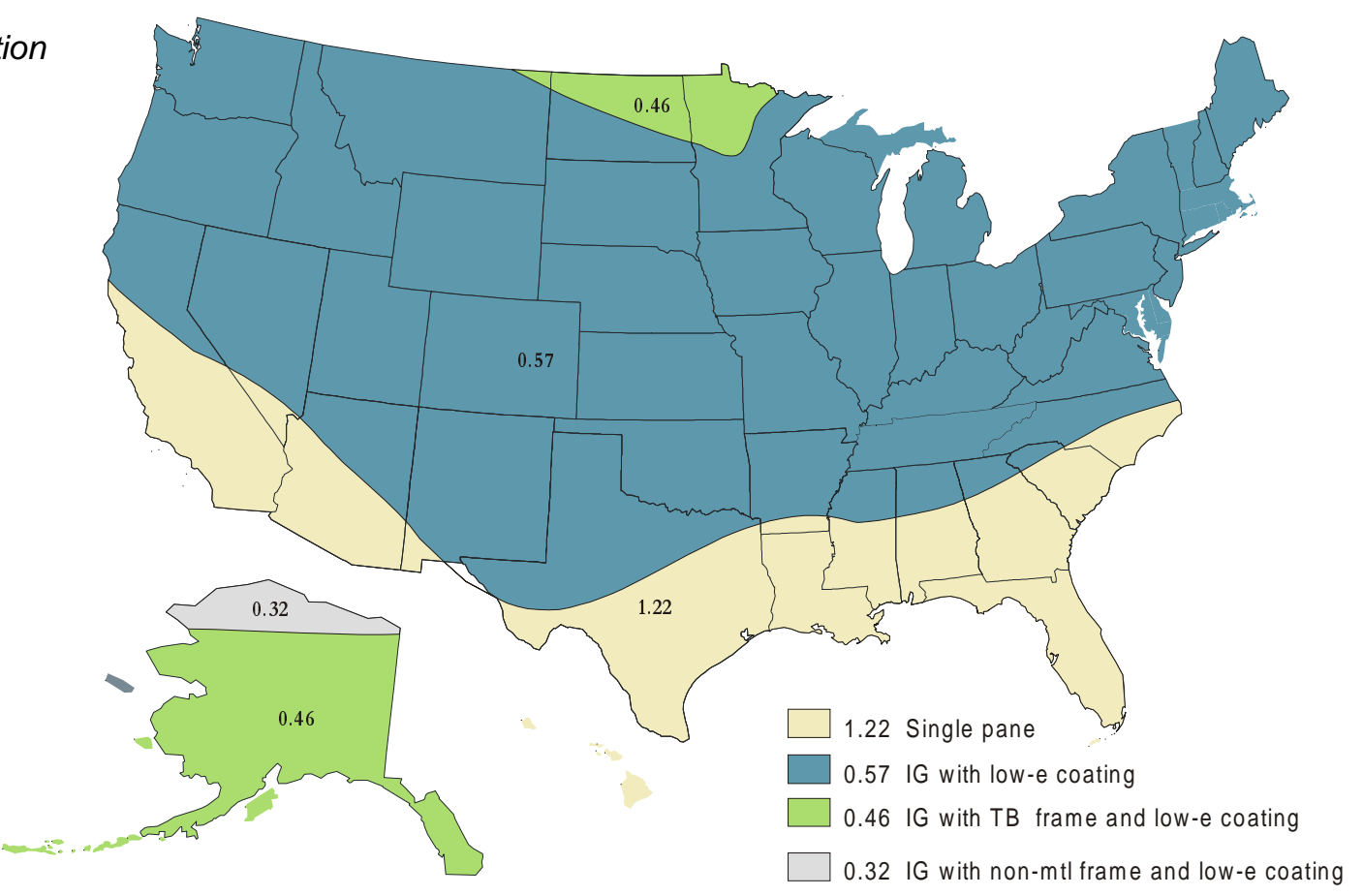

Figure 3 -

ASHRAE 90.11999 Fenestration SHGC

Requirements (0.2-0.3 WWR)

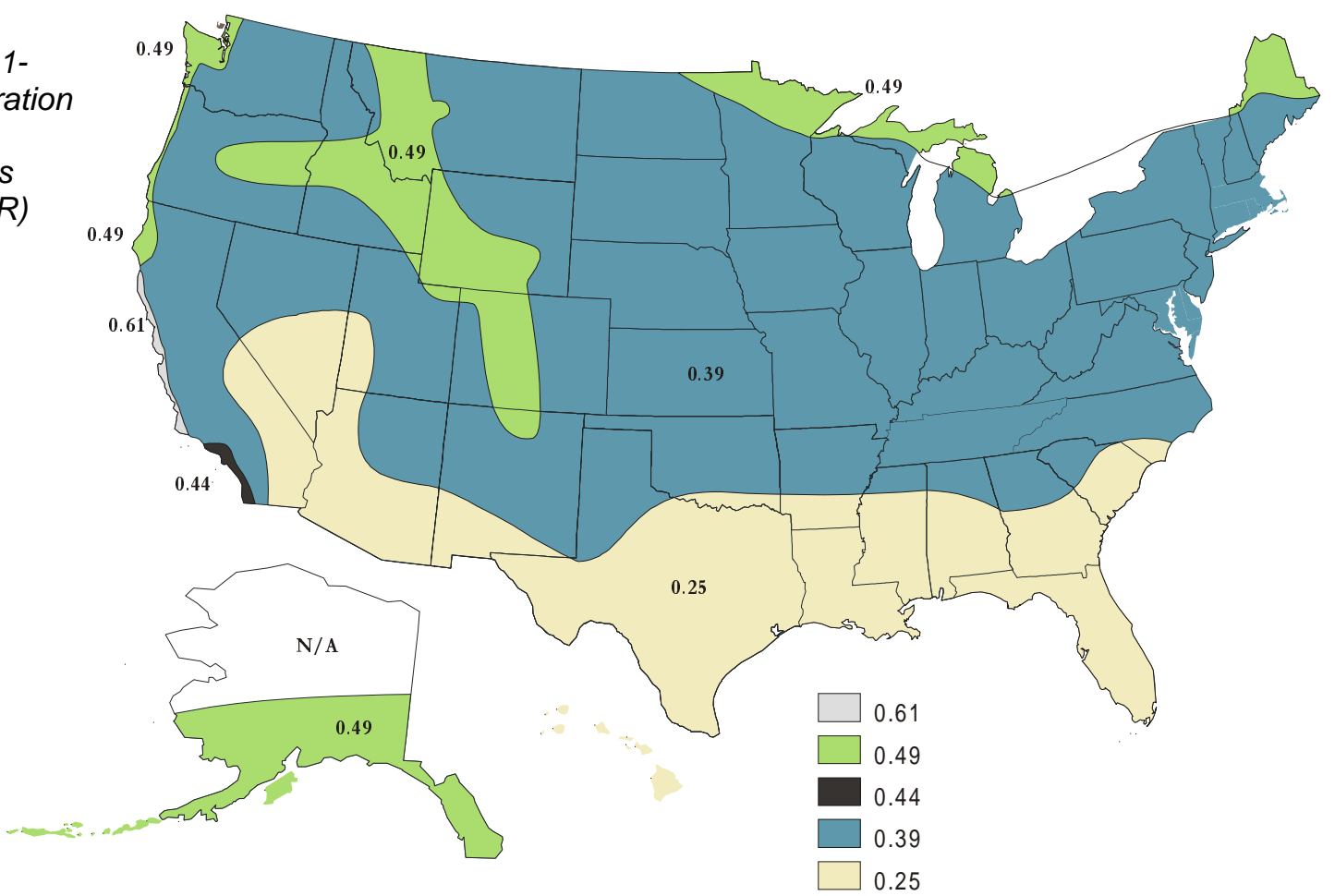


Figure $4^{23}-$ Current Use of ASHRAE Standard by State

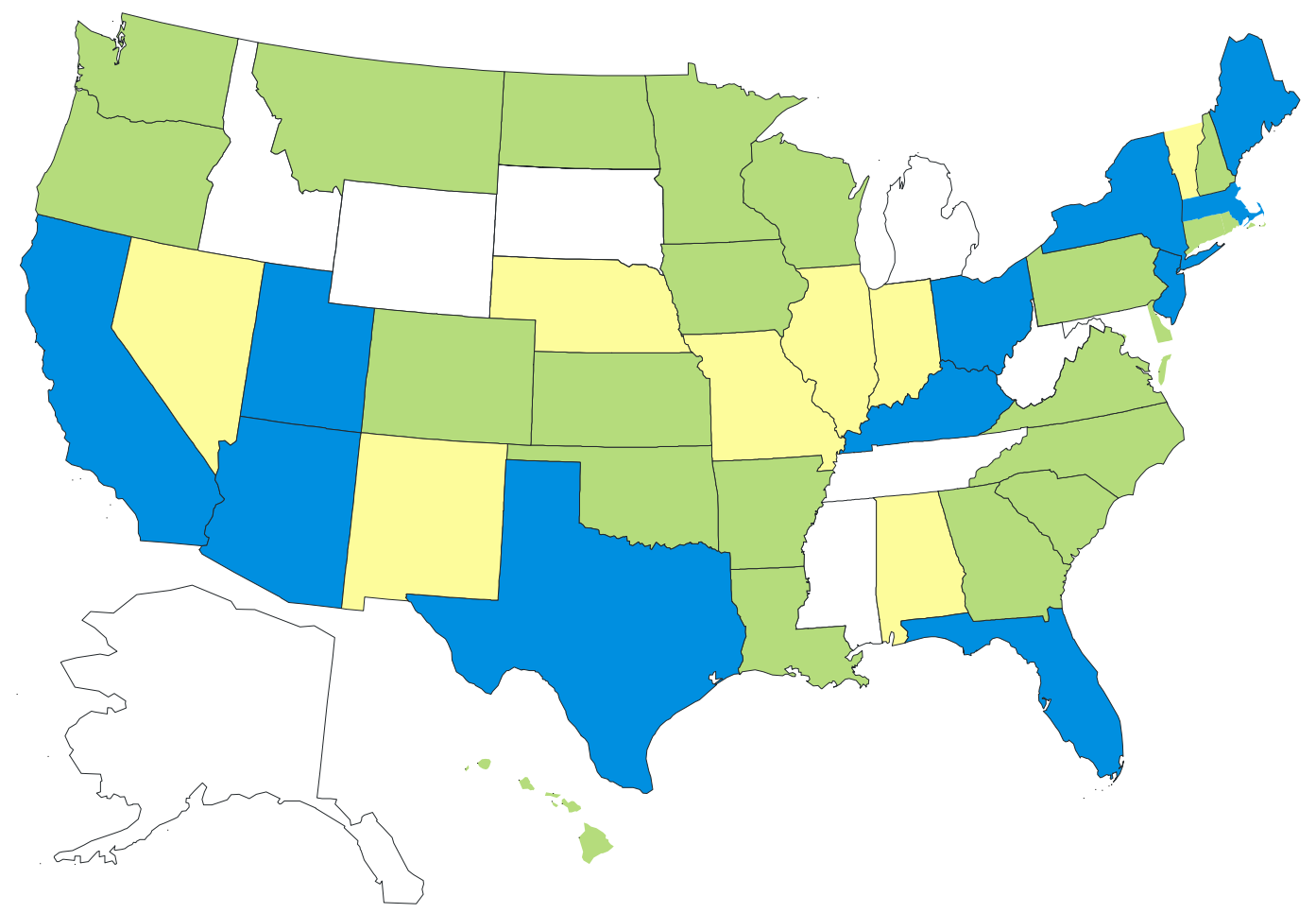

Nonresidential Energy Code Status

\begin{tabular}{|l|}
\hline $\begin{array}{l}\text { ASHRAE 90.1-1999 or equivalent being adopted (11 } \\
\text { states) }\end{array}$ \\
$\begin{array}{l}\text { ASHRAE 90.1-1989 or equivalent being adopted (23 } \\
\text { states) }\end{array}$ \\
$\begin{array}{l}\text { State owned only (8 states) } \\
\square\end{array}$ \\
Weaker/none (8 states)
\end{tabular}

Code adoption in AZ, CO, ID, HI, and ND depend on voluntary adoption by local jurisdictions.

\section{Product Certification and NFRC}

The NFRC conducts an energy certification and labeling program for fenestration products and systems. Currently, NFRC is the only organization recognized by the USDOE for developing energy performance standards, and related certification

Data obtained from The Building Code Assistance Program, http://www.bcap-energy.org. Current code use as of January 2002. 
programs, for fenestration products. Most shop-built fenestration products have NFRC labels and are listed in the NFRC-certified products directory. NFRC data for a product assures that the U-factor, SHGC, and VLT are calculated and/or tested using consistent and accurate methods. The label also enables building officials to verify that products meet energy performance criteria during their field inspections.

Advocates of NFRC feel the goal of the system is to address the combination of glass and frame performance when trying to improve the energy efficiency of nonresidential products. PGMs have come a long way in improving glass performance, and frame performance is considered the weak link of the nonresidential fenestration market. The residential market consists of many of wood and vinyl frames, as well as some aluminum frames, but the nonresidential market is still primarily aluminum framing and has relied on glazing technology to improve overall product performance.

The application of NFRC standards to site-built fenestration products is new and just beginning to occur. ${ }^{24}$ Most architects feel the NFRC rating system is a step in the right direction and that the process will become smoother as more site-built glazing systems are rated.

Some glazing contractors criticize the rating system for site-built fenestration, stating that the process hinders innovation, limits design, and can over emphasize frame U-factor (frame design and type of thermal break) if the glazing-to-frame ratio is higher for the actual product than for the standard framing size. There is criticism of having to use a standard mock-up to test curtain wall glazing systems.

One industry expert is concerned that transferring the NFRC system to site-built applications could bureaucratically bog down the market. He states that having a third party certify performance characteristics is out of line with the designing of nonresidential structures. He feels third-party certification adds unneeded cost and time to a project. A suggested alternative is to design a program like WINDOW 5.0 to simulate performance levels of entire fenestration systems. Results from a "certified" program like this could be required and documented on each project, but no other requirements would be needed.

Frame suppliers also feel that the NFRC system was developed for the residential market and does not smoothly cross over into the nonresidential market. The residential market uses limited glass types and has control of the overall product because it is fabricated

24 See Appendix for more information. 
before arriving at the site. The framing suppliers state that the glazing contractors generally use a glazing type that is not in the framing suppliers' simulated matrix (due to the myriad of glass types in the nonresidential market). All the glazing contractors state that a new mock-up has to be tested for each product line in each new project. Having to test for every project is regarded as a lengthy process that results in lots of paperwork and possible delays. Due to the time it takes to obtain testing results, there is also concern that test results may show non-compliance with energy codes after the glazing has already been ordered. However, in areas where this requirement has been in effect longer, such as Seattle and Washington State, contractors have found that some common frame types are used on multiple projects. Consequently, it is relatively quick and inexpensive to have the computer simulation done to add new glass options to the existing glazing options matrix. In these cases, no additional testing is required by the NFRC program. As the NFRC U-factor, SHGC, and VLT ratings are based on simulations, any party in the process, from architect to glazing contractor, can arrange for simulations to be done and have a sense of how the product will perform without the need to wait for a mock-up to be produced, shipped, and tested.

Some interviewees support a more self-certifying method, such as the American Architectural Manufacturers Association (AAMA)'s "chart certification" system. ${ }^{25}$ The AAMA system uses the same tools as NFRC, but separately measures the center of glass performance, edge of glass performance, and glass-to-frame ratio. It is based on generic frame and edge performance, not specific product performance as required with NFRC ratings. A chart shows overall performance for various combinations of these three variables. It also allows architects to immediately know if the glazing system they are choosing is adequate, and they can make adjustments if necessary. Combining a system like AAMA's chart with an Energy Star-like system to simply rate different levels of performance is also a suggestion. Some interviewees claim that the perceived complexity of the NFRC system prevents consumer/owners from using the NFRC label certificates to compare site-built fenestration options.

Those dissatisfied with NFRC also consider the certifying costs to be prohibitive, quoting figures as high as $\$ 35,000$ per project. $^{26}$

25 Currently, AAMA does not have an active certification program. NFRC is the only organization recognized by the federal government to administer a certification program for rating the energy performance of fenestration systems.

${ }^{26}$ Appendix A indicates that the highest NFRC labeling cost scenario is $\$ 18,550$. 
Seattle architects support the NFRC process and state the framing suppliers need to get serious about getting their systems certified. Seattle glazing contractors that are experienced with NFRC also support the certification process. They state that while the process is initially cumbersome, it is quickly learned and has not resulted in any delays. These glazing contractors quote certification costs at $\$ 5,000$ to $\$ 10,000$. These same glazing contractors, however, state that on retail projects, they usually just use the default table, even though it is punitive, because the process time for certification is too long.

\section{Other Trends}

\section{Self-Cleaning}

Glazing

Increased

Awareness of "Green" Buildings
LCA for Fenestration
Increased Desire for Larger Pieces of Glass
This fenestration has recently hit the market and is expected to become popular. It has an exterior coating on the first surface that reduces dirt adhesion to the glass.

There is greater demand for public buildings to be "green." This has caused architects to begin to review performance, as well as the aesthetic characteristics of fenestration products. Traditionally, PGMs would match required performance with a look that the architect desired. Now architects in large firms are using programs like THERM to run simulations. Architects are also beginning to look at total product (frame + glass) performance. If the performance analysis shifts to architects, then high performance fenestration products will become popular.

Window manufacturers are working to design a generally accepted method to evaluate the environmental impact of product performance and materials (such an evaluation is referred to as a life-cycle assessment (LCA)). Window manufacturers are heavily involved with wood framed fenestration, which would rank highly in such a fenestration life-cycle analysis.

There has been an increase desire for larger pieces of glass in the design of structural wall systems. 


\section{Barriers}

\section{Custom Fabricators}

Custom temperers/fabricators can be an innovation bottleneck. This is a relatively small group in the industry that sees a large percentage of the glass going into nonresidential buildings. One fabricator/temperer interviewed states that there are so many different energy-efficient options that it can get confusing. They are not able to stock everything, so they must choose. This means they might not always have the best combination of glass characteristics to achieve a certain performance level. Fabricators/temperers are reactive to market demand and only stock what is in high demand. This group has a large impact on what type of glazing is available at a fair cost. Informing architects and owners of the cost benefits of energy-efficient fenestration will increase demand and motivate fabricators to stock these products.

\section{Owner Incentive}

Many interviewees comment on the lack of incentive for owners to use energy-efficient products. Owners commonly sell buildings after construction is completed, which creates no incentive for them to invest in technologies that will reduce operating costs. There is also little incentive for owners who operate the building. Owners will simply choose lower performing materials and raise rental prices to absorb the higher operating costs. This has no repercussions because the rent increase for energy costs is relatively minimal and owners generally have tenants secured before the building is built.

\section{Initial Cost}

Producing thermally efficient fenestration is similar in cost to producing inefficient fenestration, but changing the production process can be expensive. New equipment and new business protocols are necessary to adjust to a new product. Converting framing from thermally unbroken aluminum to thermally broken aluminum is a prime example. Once established, production costs of the two frames are similar. The initial cost of the 
change, however, has caused many fabricators/frame suppliers to continue in their current mode of providing products that are less energy efficient.

\section{Reliability Concerns}

It is hard to change the mind of someone who had a bad experience with an energyefficient product. Reliability in high-rise buildings is a costly liability. Curtain walls are meant to last much longer than typical residential punched openings. The industry only wants to use technologies in curtain walls that have a successful history and have proven reliability. The industry is wary of trying new technologies, such as warm edge spacers.

\section{Traditional Bid Process}

The bid process makes an integrated approach difficult. Once everyone is on board, it is too late. Plus, HVAC and lighting is traditionally done after the building skin is designed and often constructed. Groups are discouraged from using their resources to produce a design together unless they can be assured the job.

An integrated approach has worked when the owner chooses the different groups and sticks with them without going through a formal bidding process. This will cost the owner more, but occurs in a robust economy where the time saved from not doing the bid process is needed. It is also more feasible in locations where retail prices are high enough to cover this extra cost. ${ }^{27}$

Codes could possibly promote an integrated approach. An incentive program that would make it financially feasible to bypass the bid process is another possibility. Energy consultants might provide another opportunity to achieve an integrated approach, but currently energy consultants are not part of the project at the budget phase.

Design-build puts the developer in a position of liability. Insurance companies do not want to insure this type of product. Design-build happens when the architects want it. Designbuild projects work well to put the design team together, but do not always produce the best result because incentive clauses promote the cheapest possible initial design.

27 The $1^{\text {st }}$ and Howard building in San Francisco is a good example of this. 


\section{Performance Options in Energy Codes}

The performance option makes it difficult for window manufacturers to know what kind of fenestration product will be in demand. They invest in manufacturing a high performing product assuming there will be a code-induced demand. If the codes end up allowing fenestration performance to be traded away, the manufacturers lose money. This possibility deters manufacturers from investing in energy-efficient technologies.

California's Title 24 (before the 2001 update) is an example of code language that did not result in the use of energy-efficient products in many cases.

\section{Downsizing is a Hard Sell}

Choosing air conditioning systems in nonresidential buildings is a more complex process than residential HVAC selection. There are professionals involved, the systems are larger and more complex, and specifications tend to rely on previously used sizes. The higher initial cost associated with high performance fenestration products is currently much more tangible than the increased comfort or HVAC downsizing gained from high performance fenestration. Furthermore, choosing energy-efficient products without downsizing the HVAC system can result in "short cycling" the HVAC equipment, which is inefficient and can damage the equipment or shorten its service life.

\section{Vague Specifications}

Concerns exist regarding vague specifications writing by architects. Coaters feel glazing contractors use the vague specifications to supply a cheaper, lower performing product than originally intended.

\section{Improper Design}

One national glazing contractor states that storefront designs are often used for ribbon windows in office buildings. This results in a higher air infiltration rate and lowers thermal efficiency. The same glazing contractor also feels that architects do not follow AAMA recommendations on CRF values. 


\section{Historic Buildings}

Architects are typically resistant to high performance fenestration products during the renovation of historic landmark buildings. They want a product that is similar to the existing fenestration. Many of these products are punched opening windows made from wood, and an IG unit in a wood sash can become too heavy. One framing supplier interviewed states they are working to promote aluminum framing systems that look like wood from the exterior.

One window manufacturer, who is heavily involved in the retrofit market for traditional educational buildings, states that clear glass is commonly used. Old, clear single glass fenestration in these educational buildings are being replaced with clear IG units.

Aesthetic concerns have created resistance towards including a clear, low-e coating in IG units. 


\section{Opportunities}

The opportunities listed below are those identified during interviews with industry representatives. These actions, if implemented, could significantly increase the energy efficiency of fenestration design. This section does not list all possible opportunities, only ones that have repeatedly come up during the interviews. Further review of the fenestration market would most likely reveal many other effective ways to improve the energy efficiency of the fenestration market.

\section{Reduce the Use of Monolithic Glass}

PGMs, fabricators, glazing contractors, and some industry experts suggest that energy codes ought to allow only insulated glass. Going from single to double pane is a big energy efficiency improvement by itself. Furthermore, coating is a simple addition to the manufacturing process of an IG unit and quickly becomes cost-effective. The concern that low U-factor fenestration in climates like Florida prevents buildings from cooling off at night seems to be debatable: building fans have a significantly greater effect in cooling a building than heat transfer through the glass, but fans then need to be bought and installed and they will consume energy while running. Florida, the Deep South, and Southern California are identified areas where fabricators ship monolithic glass directly to a site.

One glazing contractor states that IG unit installation is more labor intensive (more manpower) than monolithic glass, due to the heavier weight (85 lbs per worker). Other than weight, no extra work is involved in installing an IG unit instead of monolithic glass

\section{Analysis Tools}

Many interviewees feel more analysis tools are needed. One architect states that, in general, architects are in favor of "green" buildings, and will push for energy-efficient fenestration products if they are armed with the proper information to persuade clients.

The industry needs to provide a tool to effectively identify markets where investment in energy-efficient technology provides the best payback. This could be in the form of a web site that correlates fenestration cost and performance with building location. This tool 
could also show the advantages of effective daylighting use. The web site would need to use accurate and up-to-date cost information to allow the payback to be calculated. The accuracy of the analysis tool is essential. Architects stress that clients are hesitant to endorse energy-efficient technologies when the architect can only provide vague estimates of the costs and benefits.

The industry also needs to provide a better way to quantify the benefits of daylighting. Architects state that daylighting is a big seller of energy-efficient technology. Enabling architects to tailor daylighting benefits to a specific building will help persuade clients to make the investment.

Better computational tools are needed to quantify fenestration performance, thereby simplifying the selection process. The industry should design a simple and accurate grading system that everyone will easily understand. One possibility is a region-specific Energy Star label for nonresidential products so the architects do not have to juggle SHGCs and U-factors in their head. Promoting NFRC ratings could also simplify this process if the ratings can be generated by the designer in a timely manner and at a reasonable cost.

One concern raised is that current parameters like U-factor, SHGC, and VLT are used, but their benefits are not necessarily linear. For example, a product with twice as much VLT is not necessarily twice as good as the base product. Once U-factor drops below 0.5 , the benefits are not linear to U-factor reduction. These types of comparisons need to be more accurately made, rather than defaulting to "the lower the better."

Another concern raised is that conflicting interests, such as the air conditioning and fenestration industries, may make it difficult to properly access the benefit of energyefficient products. For example, obtaining accurate HVAC cost information to determine if downsizing is cost-effective may be difficult since downsizing would adversely affect the air conditioning contractor.

\section{Help Owners Understand the Benefits}

Many interviewees feel building owners/project developers need to be influenced to instigate change. If an architect specifies a high performance product, it may be valueengineered out, because the clients are asking for the cheapest option. By providing owners with a better understanding of the payback periods associated with energy efficiency and the other benefits associated with high performance fenestration, they will be more inclined to choose energy-efficient options. This information should be readily 
available to owners who also operate the building. More energy-efficient widows will end up in buildings if the owners better understand their value.

Interviewees also suggest working with manufacturers to target owners/residents and show them how energy-efficient products are related to the things they care about. Condensation is a big concern with building owners. The industry should promote energy-efficient designs that also reduce condensation, such as silicon structural glazing (no exterior metal). Thermal comfort next to glazing is another strong selling point. Wellinsulated fenestration allows tenants to utilize perimeter areas, which increases the usable floor area of the building. Owners need to understand how larger glazed openings, which attract tenants, must be high performance to maintain thermal comfort. Some architects state that concern over glare rarely results in the specification of high performance products. Owners tend to choose shading devices to prevent glare problems. One interviewee suggests emphasizing energy efficiency as "modern design" to capitalize on the desire of owners and big developers not to build outdated buildings.

In addition, interviewees suggest reaching the owners through the glazing industry groups that deal directly with owners, such as architects, window manufacturers, and glazing contractors. Creating an incentive for these groups to communicate the benefits of high performing glazing is an effective way to educate owners.

\section{Education}

More information about energy-efficient fenestration products needs to reach architects. There is a lag time between when new technologies hit the market and when architects are familiar with that technology. Architects do not know much about glass because it is not an item of focus in architecture school. This is also due to the market itself, as the shakedown in the early 1990s reduced the number of developers and glazing contractors with a strong expertise in the field. The result has been less understanding of energy efficiency protocol. Furthermore, PGMs used to heavily invest in educating architects, but this is not as common anymore and architectural tech services at PGMs have been greatly reduced. This disproportionately affects smaller architecture firms that lack the size or resources to directly communicate with the PGMs or participate in training programs. The manufacturer of a high performance fenestration system states that only large, metropolitan architecture firms specify their product. There are many architects who still do not understand the benefits of low-e and think a dark tint is necessary to significantly reduce the SHGC. Many architects and mechanical engineers are not familiar with newer energy-efficient products. Architects may not be familiar with low-e coatings. Mechanical engineers may not understand how a low-e coating can affect the 
sizing of the HVAC system. Designers will not specify technologies they do not know. Greater education about glazing options and their associated benefits, such a daylighting, would result in greater specification of energy-efficient fenestration.

One window manufacturer suggests that architects attempt to specify performance, rather than just prescriptive, product characteristics. If an architect only specifies "low-e glazing," the fenestration will get value-engineered to the lowest performing, low-e glazing available.

Educating glazing contractors about the advantages of energy-efficient products is also important. There is a perception that energy-efficient fenestration products have a very long payback period. This is hard to disprove because the payback for fenestration is much harder to measure and quantify than the payback for lighting or HVAC systems. Some interviewees also suggest educating glazing contractors about the NFRC process.

\section{The Replacement Market}

One PGM involved with fabrication estimates $50 \%$ of its glass is going into the replacement market. Pushing energy-efficient replacement fenestration, especially with big property management groups, reaches a lot of buildings and has a significant effect. Interviewed glazing contractors feel replacement fenestration is being specified at the same performance level as fenestration for new buildings (excluding historically significant buildings).

\section{Glazing Films}

Glazing films have the opportunity to increase the energy efficiency in buildings where fenestration replacement is considered too expensive or undesired. Recently built buildings with fenestration that perform poorly or cause discomfort are good candidates for glazing films. In the nonresidential market, the films are primarily used for security purposes and to reduce energy usage. Films are also used to minimize hot and cold spots in the building and to reduce glare. The use of glazing films is not driven by code because films are generally used for retrofit applications.

The film industry markets to architects, but their primary targets are building managers and owners. Much of their marketing involves making the industry aware of glazing films as an option to improve energy efficiency in a building. The film industry is separate from the glass industry and generally deals with a different type of client. Upgrading a building with glazing films is not the same level of retrofit as replacing entire glazing. Owners 
generally compare the energy savings of films with lighting or HVAC upgrades. One of the big energy efficiency advantages of films is that they have a significant impact on reducing peak demand.

Glazing films are typically purchased and applied through a dealer/applicator who specializes in this product. Warranties for the film and application usually run 10-15 years, although architects and owners should be aware that the application of glazing films to IG units without the involvement of the IG manufacturer may void the IG warranty. Film appearance ranges from highly reflective to very light, neutral colors. Typical high VLT performance values include a VLT of 0.57 and an SHGC of 0.42. Typical low SHGC values include a VTL of 0.11 and an SHGC of 0.22 . Most films sold for nonresidential buildings are neutral in color (very light gray).

\section{Energy Efficiency Programs}

Rebate programs, investment credits, or other financial assistance, if marketed well, can do a good job promoting high performance fenestration products. Many interviewees state that cost is the main barrier keeping energy efficient features out of buildings. Owners/architects choose lower performance products because of the lower initial cost. Any incentive that could reduce the burden of high initial cost would be beneficial. The programs should function within the normal chain of business and respond at the pace of business. Information on the programs should target the PGMs and coaters. If they know of the incentives, they will exert the effort to promote these rebates to architects and glazing contractors. Promoters of energy-efficient fenestration products should work with window manufacturers in the industry who could benefit from this promotion.

Rebuild America and performance contracting with energy service companies are examples of successful programs. A few interviewees suggest promoting an Energy Star program for commercial windows (just punched openings).

\section{Better Communication Among the Design Team}

Some architects in large firms feel that integrated teams are the most effective way to incorporate energy-efficient technology. Architects and engineers generally work for different groups and do not communicate until the project design is set. They stress communication during the design process and the need to work with progressive engineering firms that embrace innovative technology. 


\section{Promote High Performance Tints}

There is still a strong market for older, lower performing tints. One PGM states that their big seller is a traditional blue tint, even though they carry other, higher performing, blue tints. Another PGM states that their traditional blue and green tints still hold more market share than their spectrally selective blue and green tints. Lack of knowledge and architects just specifying what they know are the reasons cited for the popularity of older tints.

\section{Provide Showcase Buildings}

Showcase buildings can highlight fenestration's effect on energy use and its effect on the aesthetic feel of the building. Case studies are a great way to market the comfort and dollar savings associated with energy-efficient products. This will increase architects' confidence in high performance fenestration and provide examples that an architect can cite to a client. The case studies should be directed towards architects to encourage them to sell and promote these technologies to their clients.

\section{Address Energy Efficiency at the Planning Stage}

The building budget is often designed in a way that the project is over budget from the beginning. This makes it very difficult to persuade an owner/developer to pay more for an increase in fenestration performance. This cost needs to be addressed in the planning stage, not after the project has begun and is already over budget. 


\section{Energy Savings Potential}

Nonresidential buildings in the U.S. consume a total of 15.4 quads $\left(4.5 \times 10^{12} \mathrm{kWh}\right)$ of primary energy, or $16 \%$ of all the energy used in the country. Of these 15.4 quads, an estimated 1.1 quads are used for space conditioning the thermal loads imposed by glazing (heating 0.5 quads and cooling 0.6 quads). ${ }^{28}$ In addition, it should be noted that lighting accounts for 3.8 quads in commercial buildings. Past research has indicated that daylighting has the potential to offset approximately one-fourth of the electric lighting requirements in commercial buildings. Thus, there is approximately another 1 quad of lighting energy use that could be saved through the choice of fenestration systems and installation of lighting controls.

Figure 5 - Heating and Cooling Loads Imposed by Nonresidential Glazing $^{29}$

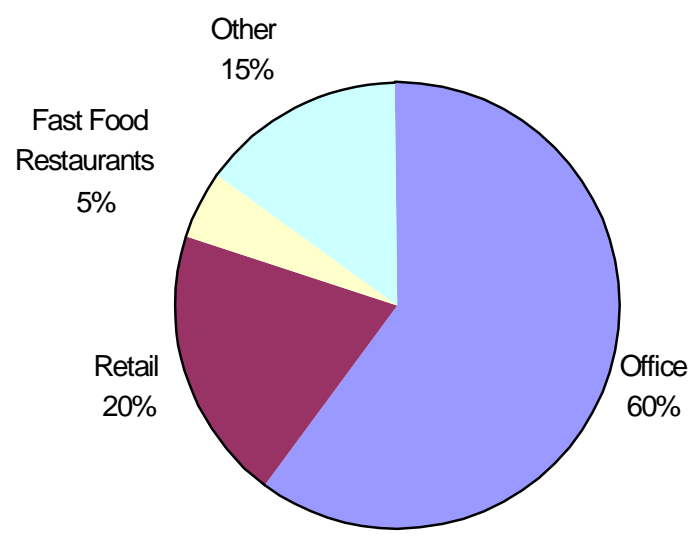

Heating (0.5 quads)

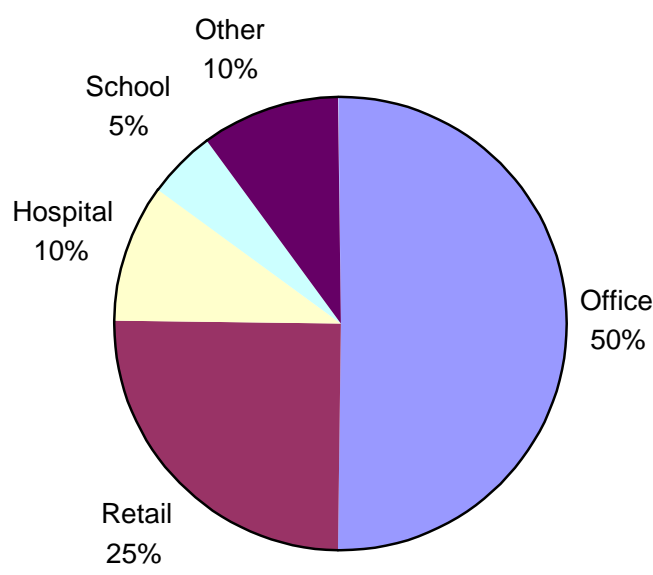

Cooling (0.6 quads)

The technological potential for reducing the heating and cooling impacts of glazing in commercial buildings is quite high. While a definitive analysis is outside the scope of the project, high performance fenestration can reduce heating impact to zero ${ }^{30}$ during

All data based on 2001 BTS Core Data Book, USDOE/ EERE, Office of Building Technology State and Community Programs.

Huang, Joe, and Ellen Franconi. Commercial Heating and Cooling Loads Component Analysis. LBNL Report 37208. June 1998.

30 The high internal heat gains in commercial buildings contribute to making a zero heating impact achievable. 
occupied hours (or even use solar gains to provide a direct heating contribution to the building). However, most heating occurs during morning warm-up (5 AM to $7 \mathrm{AM}$ ) when the building is unoccupied, and lights and equipment have not yet been turned on. Through the use of commercially available, selective glazings, which reflect the solar infrared, cooling impacts can be reduced by approximately $50 \%$. Technologies currently in the research stage (such as electrochromic glazings) can reduce cooling loads even further.

The technological potential from applying existing (but underutilized) and emerging efficient glazing technologies and complimentary lighting control technologies to the commercial building sector is quite high - on the order of 1.5 to 2 quads. However, due to the long lifetime of glazings in commercial buildings, the time it will take to achieve the full potential is long. Incremental savings can be expected every year. For example, the projected annual savings from the 2001 update of the California energy code (Title 24) is on the order of 76 gigawatt hours. ${ }^{31}$ A significant portion of these savings is due to the increased stringency of the state's fenestration requirements. An increase in the rate of savings could also be expected from programs that accelerate the use of retrofit products (namely applied films and storm windows).

${ }^{31}$ California Energy Commission, Energy Committee Proposed Standards, Volume IV, 2000. 


\section{Glossary of Terms}

Cathodes. A metallic device that is bombarded by electrons. Molecules from the cathode sputter off and are deposited on the surface of the glass, which has the opposite electric charge as the cathode. Cathodes are used in sputter coating equipment.

Ceramic Frit. A ceramic paint comprised of minute glass particles and pigment mixed together in a medium. The ceramic frit is applied to glass, usually with a silk-screen process, and then fired to create a permanent opaque coating. The process is very similar to applying a glaze to pottery.

Coaters. A group of companies that buy flat glass from PGMs and apply a sputter coating. Coaters may also be fabricators, since some also temper the glass and fabricate it into IG units (see Fabricators).

Cullet. Recycled glass, excess glass from a previous melt, or waste trimmed off when cutting glass to size. Cullet is an essential ingredient in the raw batch during glass making because it facilitates melting.

Curtain Wall. An exterior building wall which carries no roof or floor loads and consists of a combination of glass, metal, and other surfacing materials supported by a metal frame.

Edge Deletion. The process of removing a sputter coating from the edges of a pane of glass before fabrication. The coating is removed to ensure a durable, insulated glass seal.

Fabricators. Fabricators are companies involved with fabricating glass that they receive from PGMs. Fabricators are not involved with placing sputter coatings on glass, but may fabricate sputter-coated glass into IG units. Tempering and laminating may also be done by a fabricator.

Float Line. The equipment used to manufacture glass by a process of floating the glass on a bed of molten tin.

Post-temperable Coating. A sputter coating that can be applied to glass before it is tempered. This allows fabricators to stock standard sizes of sputter-coated glass, which can then be cut and tempered by the fabricator. 
Primary Glass Manufacturer (PGM). Companies that produce glass on a float line from sand and cullet.

Pyrolytic Coating. A metallic oxide coating applied while the glass is hot and still on the float line. Pyrolytic coatings have the advantage of hardness and durability over sputter coatings and are suitable for monolithic glass.

Shading Coefficient (SC). This is the ratio of heat gain that passes through fenestration compared to that which would pass through a reference glass (defined as one-eighthinch, clear, heat-strengthened glass). SC is being replaced by SHGC as the way to rate heat gain through glass.

Shop Built. A complete glazing system, including the frame, which is factory-assembled by a window manufacturer before being sent to a glazing contractor or retailer. The glazing systems are generally punched opening windows and, occasionally, storefront products.

Silk-screen. The term used to represent the result of adding ceramic frit to glass (see Ceramic Frit).

Site Built. Glazing systems where the glass unit and the frame are shipped to the job site separately, and then assembled together on site. Site-built products include punched opening windows, curtain walls, and storefronts.

Solar Heat Gain Coefficient (SHGC). The ratio of heat gain that passes through a fenestration product compared to the amount that is incident on the exterior. SHGC is a term that is reported on NFRC labels.

Spandrel. The panel(s) of a wall located between vision areas of glazing, which conceal structural columns, floors, and shear walls.

Spectrally Selective Glass. Glass that allows a high percentage of solar radiation within the visible spectrum (visible light) to pass, while blocking most of the solar radiation not in the visible portion of the solar spectrum. The classic definition is a product that has a VLT larger than the SC, or now, the SHGC.

Sputter Coating. A multi-layered coating deposited on glass (or plastic film) in a vacuum chamber after the glass has been manufactured and cut. Sputter coatings often use a silver layer and must be protected from humidity and contact. To insure protection, sputter coatings are placed on the inner surface of an IG unit. Sputter coatings have the advantage of better U-factors (lower) and better daylighting (higher) compared to pyrolytic coatings. 
Storefront. A nonresidential system of doors and windows mulled as a composite structure. Typically designed for high use/abuse and strength. The storefront system usually is installed between the floor and ceiling.

Thermoplastic. A low conductance material used instead of aluminum or steel for the spacer in an IG unit.

U-factor. The rate of heat flow through a fenestration product that is driven by a temperature difference. U-factor does not consider solar heat gains (see SC and SHGC). The units of U-factor in the U. S. are Btu/h-o $\mathrm{F}-\mathrm{ft}^{2}$ or $\mathrm{W} / \mathrm{m}^{2}{ }_{-}-\mathrm{o} C$.

Unitized Curtain Wall. A curtain wall system that is pre-assembled by a glazing contractor before reaching the job site.

Visible Light Transmittance (VLT). The percentage or fraction of the visible spectrum (380 to 720 nanometers), weighted by the sensitivity of the eye, which is transmitted through the glazing. 


\section{Bibliography}

Building Code Assistance Program. www.bcap-energy.org. January 2002.

Ducker Research Company. "The Distribution of Residential Doors and Windows in the 1999 U.S. Market." April 2000.

Ecotope. "Baseline Characteristics of the Nonresidential Sector in Idaho, Montana, Oregon, and Washington." March 2000.

Industry Statistics. Glass Magazine. Aug. 2000.

Glass Production and Use in North America. www.GlassFact.com.

Huang, Joe, and Ellen Franconi. "Commercial Heating and Cooling Loads Component Analysis." LBNL Report 37208. June 1998.

U.S. Department of Energy/Office of Energy Efficiency and Renewable Energy. Office of Building Technology State and Community Programs. BTS Core Data Book. 2001.

U.S. Department of Energy. "Glass Industry Analysis Brief." Aug. 2000. www.eia.doe.gov/emeu/mecs/iab/glass/index.HTML. 


\section{Appendices}

\section{Appendix A -NFRC Rating and Certification Procedures for Site-Built Fenestration}

The application of NFRC rating procedures (which are based on simulation rather than testing) to site-built glazing systems is recent. While national model codes, including ASHRAE/IESNA Standard 90.1-1999 and the International Energy Conservation Code (IECC), specify the NFRC rating procedure for site-built glazing systems, these documents and many state codes have provided other compliance options that designers have tended to use in lieu of the NFRC rating procedures. The most recent California energy efficiency standard (Title 24) requires NFRC certification for site-built fenestration jobs greater than $10,000 \mathrm{ft}^{2}$ in buildings larger than $100,000 \mathrm{ft}^{2}$. The State of Washington and the State of Massachusetts also require NFRC certification for site-built glazing systems. Currently, NFRC is the only organization recognized by the USDOE for developing energy performance standards, and related certification programs, for fenestration products.

For manufactured fenestration products that arrive at the construction site as a unit, the manufacturer assumes the burden of doing the simulation (and limited validation testing) and labeling. However, with site-built glazing systems, there are multiple entities responsible for the glazing system. Architects and/or engineers design the basic glazing system by specifying the components, the geometry of the components, and sometimes, their method of assembly. An extrusion manufacturer provides the mullions and frames that support the glazing and is responsible for thermal breaks, etc. A glazing fabricator provides the glazing units, cut to size and fabricated as IG units. The glazing fabricator, PGM, or coater is responsible for tempering or heat strengthening, the tint of the glass, any special coatings, and the spacers and sealants. A glazing contractor (usually a subcontractor to the general contractor) puts the system together at the construction site and is responsible for many quality aspects. For storefront glazing and strip retail projects, common extrusions and glass types are typically used. For the glazed wall system in some large nonresidential projects, standard extrusions might be used along with a variety of glass options. For other large nonresidential projects, the extrusions for the glazed wall systems are custom designed, though the glass usually, but not always, is one of the standard options. Whenever custom extrusions or custom glass products 
are used, the design team cannot be sure of the performance without having a simulation done.

In order for a glazed wall system to be NFRC certified, one of the parties in the delivery chain must take responsibility for the overall process. The responsible party must obtain an NFRC license and establish relationships with an NFRC-certified simulation laboratory, an NFRC-certified testing laboratory, and an NFRC-certified independent agent (IA). Once these relationships are established and the proper licenses are obtained, then the following steps are carried out:

1. Identify the number of product lines that are contained in the building project.

2. Arrange for an NFRC-certified simulation laboratory to evaluate each product line.

3. Make an arrangement with an NFRC-certified testing laboratory to test each product line.

4. Prepare a mockup of each product line and send it to the testing laboratory. This will require the cooperation of the PGM/fabricator/coater and the extrusion manufacturer.

5. After reviewing the simulation and test reports, the NFRC-certified IA issues a label certificate that is kept on file in the general contractor's on-site construction office. The label certificate provides the same function as the temporary label that is required with manufactured fenestration products.

The City of Seattle reports that the glazing contractor typically takes responsibility for NFRC labeling and certification. It is common for the design team to include language in the construction specification that makes the general contractor responsible; the general contractor typically assigns this responsibility to the glazing contractor. Seattle reports that once the glazing contractor has established a relationship with an IA, a simulation laboratory and a testing laboratory, things seem to go fairly smoothly.

Seattle reports that if the process works well, it does not delay either the design or construction process. For code compliance, the NFRC label certificate is not required at the time compliance documentation is submitted for the building permit application. However, the plan checkers verify that the levels of fenestration performance shown in the contract documents (plans and specifications) and used in the compliance calculations are "reasonable" and achievable. If assumptions are made that are beyond the "reasonable" range, then the plan checker will require that the design team submit the simulation report from an NFRC-certified simulation laboratory to demonstrate that the proposed fenestration system will be able to achieve the specified level of performance. 
After the construction contract is awarded, the glazing contractor then takes responsibility for getting the simulations and tests made and for obtaining the NFRC label certificate. The IA issues a separate label certificate for each "product line." Each label certificate has the same information as the NFRC temporary label, but includes other information specific to the project such as the name of the glazing manufacturer, the extrusion contractor, the places in the building where the product line is used, and other details. The NFRC label certificate remains on file in the construction office for the building inspector to view. Afterwards, the NFRC label certificate should be filed in the building office with the as-built drawings and other operations and maintenance data. This will give building managers the information needed for repairs or replacements.

The cost of NFRC certification for site-built glazing systems varies with the size of the project. Many of the costs are fixed, so the cost per $\mathrm{ft}^{2}$ is lower in larger projects. This is why California requires NFRC testing and labeling only for larger buildings. Table 5 shows the cost for five typical scenarios. In these cases, the cost ranges from a low of $\$ 0.16 / \mathrm{ft}^{2}$ of glazing to a high of $\$ 0.94 / \mathrm{ft}^{2}$. The various components of the cost are shown in the table. Note that these costs are for first-time certification of a particular system. For other projects where the glazing contractor uses the same extrusions, but with a different glass, it is necessary to have an additional simulation done but no additional testing is required. Note also that the IA costs are on an annual basis so that the more projects a glazing contractor certifies, the lower the IA cost is on a per-project basis. 
Table 5 Projected Costs for NFRC Testing and Labeling of Glazed Wall Systems

\begin{tabular}{|c|c|c|c|c|c|c|}
\hline \multirow[b]{2}{*}{ Project } & & \multicolumn{5}{|c|}{ Scenario } \\
\hline & & $A$ & B & C & $\mathrm{D}$ & $E$ \\
\hline \multicolumn{2}{|l|}{ Number of Product Lines } & 10 & 4 & 4 & 2 & 2 \\
\hline \multicolumn{2}{|l|}{ Stories } & 50 & 20 & 10 & 6 & 4 \\
\hline \multicolumn{2}{|l|}{ Fenestration Area $\left(\mathrm{ft}^{2}\right)$} & 110000 & 50000 & 25000 & 9000 & 6000 \\
\hline \multicolumn{2}{|l|}{ Floor Area $\left(\mathrm{ft}^{2}\right)$} & N.A. & 200000 & 100000 & 84000 & 40000 \\
\hline \multicolumn{2}{|l|}{ Simulation Costs } & $\$ 4,500$ & $\$ 2,000$ & $\$ 2,000$ & $\$ 1,000$ & $\$ 800$ \\
\hline \multicolumn{2}{|l|}{ Testing Costs } & $\$ 10,000$ & $\$ 6,000$ & $\$ 6,000$ & $\$ 2,000$ & $\$ 2,000$ \\
\hline \multicolumn{2}{|l|}{ Total } & $\$ 14,500$ & $\$ 8,000$ & $\$ 8,000$ & $\$ 3,000$ & $\$ 2,800$ \\
\hline \multicolumn{2}{|l|}{$\begin{array}{l}\text { IA Certification Costs } \\
\text { (annual) }\end{array}$} & $\$ 1,800$ & $\$ 1,800$ & $\$ 1,800$ & $\$ 1,800$ & $\$ 1,800$ \\
\hline \multirow[t]{2}{*}{ NFRC Project Costs } & Member & $\$ 1,000$ & $\$ 500$ & $\$ 250$ & $\$ 100$ & $\$ 100$ \\
\hline & Non-Member & $\$ 1,000$ & $\$ 500$ & $\$ 250$ & $\$ 100$ & $\$ 100$ \\
\hline \multirow[t]{2}{*}{ Participation Fees } & Member & $\$ 100$ & $\$ 100$ & $\$ 100$ & $\$ 100$ & $\$ 100$ \\
\hline & Non-Member & $\$ 100$ & $\$ 100$ & $\$ 100$ & $\$ 100$ & $\$ 100$ \\
\hline \multirow[t]{2}{*}{ Total Costs } & Member & $\$ 17,400$ & $\$ 10,400$ & $\$ 10,150$ & $\$ 5,000$ & $\$ 4,800$ \\
\hline & Non-Member & $\$ 17,400$ & $\$ 10,400$ & $\$ 10,150$ & $\$ 5,000$ & $\$ 4,800$ \\
\hline \multirow[t]{2}{*}{ Costs/Fenestration Area } & Member & $\$ 0.16$ & $\$ 0.21$ & $\$ 0.41$ & $\$ 0.56$ & $\$ 0.80$ \\
\hline & Non-Member & $\$ 0.16$ & $\$ 0.21$ & $\$ 0.41$ & $\$ 0.56$ & $\$ 0.80$ \\
\hline \multirow[t]{2}{*}{ Costs/Floor Area } & Member & N.A. & $\$ 0.05$ & $\$ 0.10$ & $\$ 0.06$ & $\$ 0.12$ \\
\hline & Non-Member & N.A. & $\$ 0.05$ & $\$ 0.10$ & $\$ 0.06$ & $\$ 0.12$ \\
\hline
\end{tabular}

Source: James Benny, Director of Education, NFRC. May 17, 2002.

Assumptions: Simulation costs are assumed to range between $\$ 300$ and $\$ 400$ per product line with an additional $\$ 10$ to $\$ 20$ per glazing option. Testing costs are assumed to be $\$ 1,000$ per product line. The IA certification costs is assumed to be $\$ 1,800$. 


\section{Appendix B - Fenestration Product Flows in the Pacific Northwest}

The supply channel flows for the Pacific Northwest are structured similarly to the national fenestration market. The same market actors are involved, and fenestration types (curtain wall, punched opening, storefront) are produced in similar proportions to the national market. The supply flows in the following figure and tables only represent the Oregon and Washington regions (Idaho and Montana are not represented).

The supply of aluminum frames is distinctly different in this region. Thermally broken or improved framing systems are very common. Many Pacific Northwest glazing contractors who manufacture frames have made the initial investment to convert their manufacturing to thermally broken frames. This has made thermally broken frames abundant and the regional standard.

Differences between the Pacific Northwest and the national market are apparent on the demand side of the industry. Architects almost exclusively specify IG units with low-e coatings while avoiding other technologies, such as reflective coatings and argon fill. Almost all glazing going into buildings in this region is double glazed. Low-e coatings account for a significantly larger part of the Pacific Northwest market (about 70\%), compared to the rest of the country (about 40\%). Pacific Northwest storefronts are identified as the only market still resistant to low-e coatings (due to visibility concerns). Reflective coatings are not currently desired in this region for aesthetic reasons. Except for shop-built punched openings, argon gas is rarely specified. Many of the Pacific Northwest architects interviewed advocate energy-efficient design, but are wary of the benefits of argon.

The general trend in the Pacific Northwest is increased specification of IG units with a low-e coating. Low-e coatings are becoming more commonplace in the region, and codes, such as those in Seattle, are being designed to further increase low-e specification. Higher energy efficiency systems, such as triple glazing, still hold a very small percentage of the market. There is no indication that market share for these more efficient systems will increase in the future. 
Figure 6-Pacific

Northwest Supply-

Side Market Flow

Glass

Manufacturing
Primary Glass

Manufacturers

Pilkington

$P P G$

$A F G$

Cardinal

Guardian

Visteon

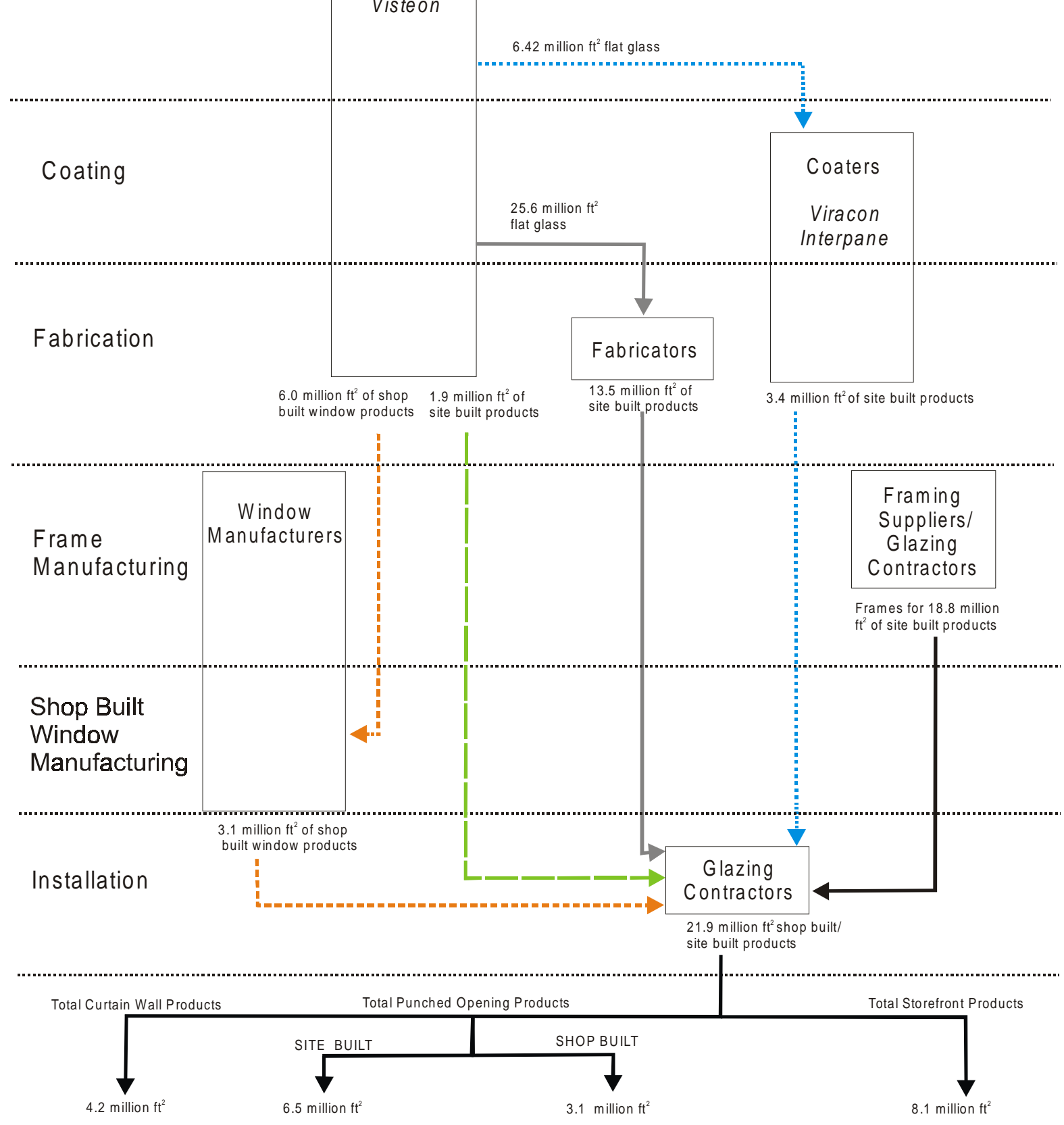

NOTE: The term "flat glass" refers to single panes of glass. The term "products" refers to final glazing products. 
Table 6-PGM

Output of

Nonresidential

Fenestration

(millions of $\mathrm{ft}^{2}$ )
Table 7 -

Nonresidential

Fenestration Input

to Glazing

Contractors

(millions of $\mathrm{ft}^{2}$ )

\begin{tabular}{|c|c|c|c|c|c|c|c|c|c|c|c|c|}
\hline \multirow[b]{2}{*}{ Flow } & \multirow[b]{2}{*}{$\begin{array}{l}\bar{\pi} \\
\text { 맘 }\end{array}$} & \multicolumn{3}{|c|}{ Type } & \multicolumn{6}{|c|}{ Glazing } & \multicolumn{2}{|c|}{ Gap } \\
\hline & & $\underline{\underline{\sigma}}$ & $\begin{array}{l}\frac{{ }^{\circ}}{\sigma} \\
\frac{\vec{E}}{\omega}\end{array}$ & 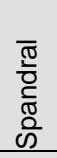 & $\frac{\bar{\Phi}}{0}$ & 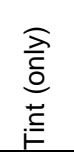 & 号 & 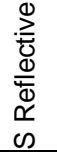 & $\begin{array}{l}0 \\
3_{0}^{1} \\
0 \\
0 \\
0\end{array}$ & 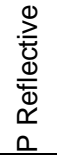 & 言 & 高 \\
\hline $\begin{array}{l}\text { PGM to Coaters } \\
\text { (unfabricated) }\end{array}$ & $\begin{array}{c}6.4 \\
\text { (flat glass) }\end{array}$ & 0.0 & 6.4 & 0.0 & 4.4 & 2.0 & 0.0 & 0.0 & 0.0 & 0.0 & -- & -- \\
\hline $\begin{array}{l}\text { PGM to Fabricators } \\
\text { (unfabricated) }\end{array}$ & $\begin{array}{c}25.6 \\
\text { (flat glass) }\end{array}$ & 0.0 & 25.6 & 0.0 & 8.8 & 8.0 & 6.7 & 0.3 & 1.3 & 0.4 & -- & -- \\
\hline $\begin{array}{l}\text { PGM to Glazing } \\
\text { Contractor }\end{array}$ & $\begin{array}{c}1.9 \\
\text { (product) }\end{array}$ & 1.6 & 0.2 & 0.1 & 0.1 & 0.1 & 1.6 & 0.1 & 0.0 & 0.0 & 1.5 & 0.1 \\
\hline $\begin{array}{l}\text { PGM to Window } \\
\text { Manufacturer }\end{array}$ & $\begin{array}{c}3.1 \\
\text { (product) }\end{array}$ & 2.8 & 0.3 & 0.0 & 1.2 & 0.8 & 1.1 & 0.0 & 0.0 & 0.0 & 1.8 & 1.0 \\
\hline Total & & 4.4 & 32.5 & 0.1 & 14.5 & 10.9 & 9.4 & 0.4 & 1.3 & 0.4 & 3.3 & 1.1 \\
\hline $\begin{array}{l}\text { Percentage } \\
\text { (by category) }\end{array}$ & & $12 \%$ & $88 \%$ & $0 \%$ & $39 \%$ & $29 \%$ & $25 \%$ & $1 \%$ & $4 \%$ & $1 \%$ & $75 \%$ & $25 \%$ \\
\hline
\end{tabular}

*Includes laminated glass.

\begin{tabular}{|c|c|c|c|c|c|c|c|c|c|c|c|c|c|c|c|c|}
\hline \multirow[b]{2}{*}{ Flow } & \multirow[b]{2}{*}{$\begin{array}{l}\bar{\pi} \\
\frac{0}{0} \\
\end{array}$} & \multicolumn{3}{|c|}{ Type } & \multicolumn{6}{|c|}{ Glazing } & \multicolumn{2}{|c|}{ Gap } & \multicolumn{4}{|c|}{ Frame } \\
\hline & & $\underline{\underline{N}}$ & $\begin{array}{l}{ }^{*} \\
\stackrel{\oplus}{\oplus} \\
\dot{\omega}\end{array}$ & $\begin{array}{l}\bar{\pi} \\
\overline{\frac{\pi}{0}} \\
\frac{0}{\pi} \\
\text { के }\end{array}$ & $\frac{\bar{\pi}}{\frac{\Phi}{U}}$ & 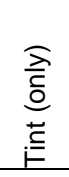 & 交 & 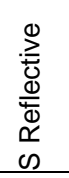 & 文 & 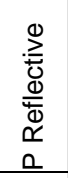 & 定 & 동 & $\begin{array}{l}\infty \\
\frac{n}{0} \\
\frac{0}{3} \\
\frac{\pi}{0} \\
\frac{0}{2}\end{array}$ & $\begin{array}{l}\frac{m}{1} \\
\frac{3}{\pi} \\
\frac{\pi}{0} \\
\frac{1}{\Sigma}\end{array}$ & $\begin{array}{l}8 \\
8 \\
3\end{array}$ & 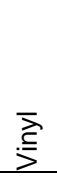 \\
\hline $\begin{array}{l}\text { PGM to } \\
\text { Glazing } \\
\text { Contractor } \\
\end{array}$ & $\begin{array}{c}1.9 \\
\text { (product) }\end{array}$ & 1.6 & 0.2 & 0.1 & 0.1 & 0.1 & 1.6 & 0.1 & 0.0 & 0.0 & 1.5 & 0.1 & -- & -- & -- & -- \\
\hline $\begin{array}{l}\text { Window } \\
\text { Manufacturer } \\
\text { to Glazing } \\
\text { Contractor }\end{array}$ & $\begin{array}{c}3.1 \\
\text { (product) }\end{array}$ & 2.8 & 0.3 & 0.0 & 1.2 & 0.8 & 1.1 & 0.0 & 0.0 & 0.0 & 1.8 & 1.0 & 0.0 & 1.2 & 1.1 & 0.8 \\
\hline $\begin{array}{l}\text { Frame } \\
\text { Supplier to } \\
\text { Glazing } \\
\text { Contractor } \\
\end{array}$ & -- & -- & -- & -- & -- & -- & -- & -- & -- & -- & -- & -- & 1.1 & 17.7 & 0 & 0 \\
\hline $\begin{array}{l}\text { Coaters to } \\
\text { Glazing } \\
\text { Contractors }\end{array}$ & $\begin{array}{c}3.4 \\
\text { (product) }\end{array}$ & 2.4 & 0.7 & 0.3 & 0.0 & 0.2 & 3.0 & 0.2 & 0.0 & 0.0 & 2.3 & 0.1 & -- & -- & -- & -- \\
\hline $\begin{array}{l}\text { Fabricators to } \\
\text { Glazing } \\
\text { Contractors }\end{array}$ & $\begin{array}{c}13.5 \\
\text { (product) }\end{array}$ & 11.3 & 1.7 & 0.5 & 3.3 & 1.8 & 6.8 & 0.1 & 1.1 & 0.4 & 10.8 & 0.5 & -- & -- & -- & -- \\
\hline Total & $\begin{array}{c}21.9 \\
\text { (product) }\end{array}$ & 18.1 & 2.9 & 0.9 & 4.6 & 2.9 & 12.5 & 0.4 & 1.1 & 0.4 & 16.4 & 1.7 & 1.1 & 18.9 & 1.1 & 0.8 \\
\hline $\begin{array}{l}\text { Percentage } \\
\text { (by category) }\end{array}$ & & $83 \%$ & $13 \%$ & $4 \%$ & $21 \%$ & $13 \%$ & $57 \%$ & $2 \%$ & $5 \%$ & $2 \%$ & $91 \%$ & $9 \%$ & $5 \%$ & $86 \%$ & $5 \%$ & $4 \%$ \\
\hline
\end{tabular}


Table 8-Total Nonresidential Fenestration (millions of $\mathrm{ft}^{2}$ )

\begin{tabular}{|c|c|c|c|c|c|c|c|c|c|c|c|c|c|c|c|c|}
\hline \multirow[b]{2}{*}{ Flow } & \multirow[b]{2}{*}{$\begin{array}{l}\bar{\pi} \\
\stackrel{0}{\circ} \\
⺊\end{array}$} & \multicolumn{3}{|c|}{ Type } & \multicolumn{6}{|c|}{ Glazing } & \multicolumn{2}{|c|}{ Gap } & \multicolumn{4}{|c|}{ Frame } \\
\hline & & $\underline{\mathbb{N}}$ & $\begin{array}{l}\stackrel{*}{0} \\
\frac{5}{\omega}\end{array}$ & $\begin{array}{l}\bar{\pi} \\
\overline{\frac{2}{0}} \\
\frac{\pi}{\pi} \\
\frac{0}{0}\end{array}$ & $\frac{\bar{\Phi}}{0}$ & 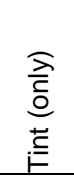 & $\begin{array}{l}0 \\
\sum_{0}^{1} \\
0 \\
\infty\end{array}$ & 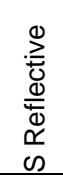 & $\begin{array}{l}0 \\
\sum_{0}^{1} \\
0 \\
a\end{array}$ & 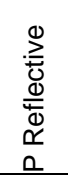 & 安 & 올 & 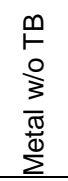 & $\frac{n}{\frac{n}{3}}$ & 을 & 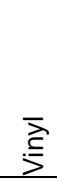 \\
\hline $\begin{array}{l}\text { Total Site-Built } \\
\text { Punched Opening } \\
\text { Products }\end{array}$ & 6.5 & 5.8 & 0.7 & 0.0 & 0.4 & 0.3 & 4.5 & 0.3 & 0.7 & 0.3 & 5.6 & 0.2 & 0.0 & 6.5 & 0.0 & 0.0 \\
\hline $\begin{array}{l}\text { Total Site-Built } \\
\text { Curtain Wall } \\
\text { Products }\end{array}$ & 4.2 & 3.2 & 0.1 & 0.9 & 0.5 & 0.4 & 2.9 & 0.1 & 0.2 & 0.1 & 3.0 & 0.2 & 0.3 & 3.9 & 0.0 & 0.0 \\
\hline $\begin{array}{l}\text { Total Site-Built } \\
\text { Storefront } \\
\text { Products }\end{array}$ & 8.1 & 6.3 & 1.8 & 0.0 & 2.5 & 1.4 & 4.0 & 0.0 & 0.2 & 0.0 & 6.0 & 0.3 & 0.8 & 7.3 & 0.0 & 0.0 \\
\hline $\begin{array}{l}\text { Total Shop-Built } \\
\text { Punched Opening } \\
\text { Products }\end{array}$ & 3.1 & 2.8 & 0.3 & 0.0 & 1.2 & 0.8 & 1.1 & 0.0 & 0.0 & 0.0 & 1.8 & 1.0 & 0.0 & 1.2 & 1.1 & 0.8 \\
\hline Total Products & 21.9 & 18.1 & 2.9 & 0.9 & 4.6 & 2.9 & 12.5 & 0.4 & 1.1 & 0.4 & 16.4 & 1.7 & 1.1 & 18.9 & 1.1 & 0.8 \\
\hline $\begin{array}{l}\text { Percentage } \\
\text { (by category) }\end{array}$ & & $83 \%$ & $13 \%$ & $4 \%$ & $21 \%$ & $13 \%$ & $57 \%$ & $2 \%$ & $5 \%$ & $2 \%$ & $91 \%$ & $9 \%$ & $5 \%$ & $86 \%$ & $5 \%$ & $4 \%$ \\
\hline
\end{tabular}




\section{Appendix C -Survey Instruments}

\section{Glass Manufacturers and Coaters}

The Interviewee What is your role in your company?

Are you knowledgeable about your company's marketing and sales of nonresidential glazing products?

Are you involved with the glass manufacturing or the window fabrication side of your firm?

Characterization of the Market

How would you describe your company's glazing market?

What percent of your market is nonresidential?

Is this product mix a reaction to market growth or is your company actively pursuing different specialized markets?

What are the most important industry trends today?

New products, new competition, partnerships, daylighting, vertical or horizontal integration, new technologies, new materials?

How are codes (ASHRAE 90.1, CA T24, regional PNW) or product standards (NFRC) influencing these trends?

How will these trends change in the next few years? Why?

What sort of challenges and opportunities do you see in the next few years?

How about trends in window characteristics?

Current Status of

What are the major glazing features that effect energy efficiency that your company

Energy-Efficient produces?

Technologies in the Market

What about thickness? Tints? Low-e coating (sputter \%, pyrolytic)?

Any technologies available that you currently do not use? Why is it not used?

Any new technologies on the horizon? Single glass technology?

Would you say process issues or market demand is determining the energy-efficient glazing feature mix? Has this mix been changing?

What has led to these changes?

What industry trends are having the greatest effect on energy-efficient windows sales/production?

What are the barriers to producing, promoting, and selling energy-efficient glazing features?

Producing: Capital investment costs in production line, quality control, shipping and warehousing, delivery issues.

Selling and promoting: code does not require them, first costs, life-cycle costing - a hard sell, lack of demand, lack of perceived need, insufficient track record, customers feel energy-efficiency feature unreliable, unable to pass on higher costs of production? Perceived costs? Actual costs?

What are the non-energy benefits that are associated energy-efficient glazings?

What benefits do you see accruing to A\&E: Fewer callbacks? Satisfied clients? Greater recognition? Staying ahead of the competition? Benefits accruing to owner/developer: 
The Motivations and Drivers in the Industry
Cost/Price of Energy-Efficient Technology

Other less noise, less sun bleaching, greater tenant comfort, lower capital costs (e.g. energyefficient windows allow for downsizing of HVAC system), higher rents, tenant retention (i.e., lower vacancy rates)?

What are the market drivers that determine the product mix?

Price___ Codes___ Other____ Demand___ Technology

How is your nonresidential glazing product sold, or distributed into the market?

Though reps? Distributors direct to glazing contractors? Window manufacturers? Contractors? Other?

How do you promote and support your product, and how far down the supply chain?

What are the major messages used to sell your (nonresidential?) glazing products? Such as reliability, quality, price, value, product selection, delivery time, energy efficiency. How could energy efficiency fit in?

How are new products developed? In-house R\&D, industry association-sponsored research, equipment manufactures, engineering firms?

Are ideas internally generated or are they a result of market demand?

A recent industry study estimated low-e at $14 \%$ of the national market. In your opinion, what percent of the nonresidential market will be low-e in five years?

What is keeping low-e from being on all windows?

What is the incremental pricing policy for the specific window characteristics?

How does the production of energy-efficient windows affect cost?

What are your pricing policies for energy-efficient windows compared to non-energy efficient windows?

Do energy-efficient features have higher margins?

Do you have any suggestions on ways to increase market penetration of energy-efficient windows?

Are there any industry experts or specific market actors that you would suggest we talk to?

Any other comments?

\section{A\&E Firms}

The Interviewee

What is your role in your company?

Are you involved with determining the type of nonresidential windows your firm specifies in construction projects?

With the nonresidential energy-efficient windows your firm installs?

Characterization of the Market
How would you describe your firm's market for construction projects?

What percent of your markets are: nonresidential? New construction/additions and renovations? Specific building types? Specific regions vs. national?

What is the total annual $\mathrm{ft}^{2}$ of project space your firm is involved with?

Is this product mix a reaction to market growth or is your company actively pursuing different specialized markets?

What are the most important industry trends today? New products materials, new competition, partnerships, daylighting, vertical or horizontal integration?

How are codes (ASHRAE 90.1, CA T24, regional PNW) or product standards (NFRC) influencing these trends? 
Current Status of Energy-Efficient Technologies in the Market
The Motivations and Drivers in the Industry
How will these trends change in the next few years? Why?

What do you see as the challenges and opportunities in glazing design in the next few years?

How about trends in window characteristics?

What process does your company typically use to determine window characteristics? Standard specs? If yes, which ones (e.g. AlA, developed in house)? Code? Glazing contractor? Outcome of the general envelope energy calculations? Developer/owner demand in the decision process? Other? Any value-engineering involved?

How does your firm typically determine window-wall ratio in a nonresidential construction project? Esthetics? Code? Client demand? Cost? Other?

Who is typically involved in the decision of window design? Architect? Owner/developer? Glazing contractor? Glazing (e.g., curtain wall) consultant? Other?

Who is typically involved in the in the decision of the exact window specification? Especially energy-efficient design?

What major window features that improve energy efficiency does your firm specify? What about thickness? Tints? Low-e coating (sputter, pyrolytic)? Aluminum unbroken? Thermally broken? Have you considered using spacers, argon fill, or heat mirror windows?

Do you expect this to increase in the future?

What would you say is generally considered a "high efficiency window" within your firm?

What percent of the windows specified are of this type?

Generally, where does your company get info on technical improvements, especially energy efficiency?

What are non-energy benefits that you see in energy-efficient window design?

What benefits do you see accruing to A\&E? Fewer callbacks? Satisfied clients? Greater recognition? Staying ahead of the competition?

What benefits do you see accruing to owner/developer? Less noise, less sun bleaching, greater tenant comfort, lower capital costs (e.g., energy-efficient windows allow for downsizing of HVAC system), higher rents, tenant retention (i.e., lower vacancy rates)?

Would you say process issues or market demand is determining the specification of more energy-efficient features?

Has this specification of energy-efficient window features been changing?

What has led to these changes?

How does code and cost factor in?

What industry trends are having the greatest effect on energy-efficient windows' penetration into the market?

How is the glazing contractor selected? Low bid? Experience? Contractor selects? Other?

How does your firm usually work with the glazing contractor?

A recent industry study estimated low-e at $14 \%$ of the national market. In your opinion, what percent of the nonresidential market will be low-e in five years?

What is keeping low-e IG glass from being on all windows?

The same study estimated only two-thirds of aluminum frames were thermally broken. In your opinion, what percent of the nonresidential market will be thermally broken aluminum in five years? 
Cost/Price of Energy-Efficient Technology

Other
What is keeping thermally broken frames from being used on everything? Cost, codes (e.g., not specified by code), value-engineering (usually specified and then not used by contractor)?

The study also indicated that only $2 \%$ of the national market was triple glazing. Where do you estimate it to be in five years?

What is keeping advanced energy-efficient window designs from gaining market share?

In general how does energy efficiency fit into your firm's marketing strategy? What part do windows play?

Do you ever use life-cycle cost in promoting energy-efficient windows to clients?

Generally, how much more is your firm willing pay for energy-efficient windows? In terms of $\%$ increase or life-cycle cost?

How do energy-efficient window features affect cost?

Does including energy-efficient features in a project improve the chances of getting a competitive bid?

Do you have any suggestions on ways to increase market penetration of energy-efficient windows?

Are there any industry experts or specific market actors that you would suggest we talk to?

Any other comments?

\section{Glazing Contractors}

The Interviewee What is your role in your company?

Are you knowledgeable about the type of nonresidential windows your company installs?

Characterization of How would you describe your firm's market for glazing installation?

the Market

What percent of your markets are: Nonresidential? New construction/additions and renovations? Specific building types? Specific regions vs. national?

Is this product mix a reaction to market growth or is your company actively pursuing different specialized markets?

What are the most important industry trends today? New products, new competition, partnerships, daylighting, vertical or horizontal integration?

How are codes (ASHRAE 90.1, CA T24, regional PNW) or product standards (ANSI) influencing these trends?

How will these trends change in the next few years? Why?

What sort of challenges and opportunities do you see in the next few years?

How about trends in window characteristics?

Current Status of

Energy-Efficient

Technologies in the Market

What is your company's window installation component product mix?
Storefront Site fabricated Shop fabricated Curtain wall (vision \% spandrel \%)
What major window types does your company install?
Where do you typically purchase your window materials?
Frames: Direct from manufacturer \%? From parent company\%? Distributor?
Glazing: Glass manufacturer? Distributor?
What industry trends are having the greatest effect on nonresidential window energy efficiency? 
The Motivations and Drivers in the Industry
Cost/Price of Energy-Efficient Technology
What sort of barriers do you feel are preventing a more systems approach to façade design?

Such as incorporating glazing design with lighting design? Describe.

What are the market drivers that determine the type of nonresidential window energyefficient features? Price? Codes? Other? Budget (only $\$ 100 \mathrm{~K}$ for windows)? Architects? Owners?

What are the major messages used to sell your services? Such as reliability, quality, durability, ease of instillation, price, value, product selection, just-in-time, comfort, energy efficiency?

How could energy efficiency fit in?

How are window characteristics determined?

Tints, framing, low-e, other spectrally selective qualities, U-value, and SHGC?

Are they part of the decision process (on what \% of projects)?

Who typically determines the window specifications and how are they determined? Do you play a major part in the decision process?

How do these different window characteristics sell themselves?

Any value-engineering involved?

A recent industry study estimated low-e at $14 \%$ of the national market. In your opinion, what percent of the nonresidential market will be low-e in five years?

What is keeping low-e IG glass from being on all windows?

The same study estimated only two-thirds of aluminum frames were thermally broken. In your opinion, what percent of the nonresidential market will be thermally broken aluminum in five years?

What is keeping thermally broken frames from being used on everything?

The study also indicated that only $2 \%$ of the national market was triple glazing. Where do you estimate it to be in five years?

What is keeping advanced energy-efficient window designs from gaining market share?

What would you say is generally considered a "high efficiency window" within your firm?

What percent of the windows specified are of this type?

How does the production of energy-efficient windows affect cost?

What are non-energy benefits that you see in advanced energy-efficient window design?

What benefits do you see accruing: Fewer callbacks? Satisfied clients? Greater recognition? Staying ahead of the competition?

Benefits accruing to owner/developer: Less noise, less sun bleaching, greater tenant comfort, lower capital costs (e.g., energy-efficient windows allow for downsizing of HVAC system), higher rents, tenant retention (i.e., lower vacancy rates)?

Installing: quality control, installation process different (e.g., learning curve), and availability and delivery issues?

Selling and promoting: Code does not require them, first costs, life-cycle costing - a hard sell, lack of demand, lack of perceived need, insufficient track record, customers feel energy-efficient features are unreliable, unable to pass on higher costs of production? Perceived costs? Actual costs?

What are your pricing policies for energy-efficient windows compared to non-energy efficient windows? 
What is the incremental pricing policy for the specific window characteristics?

Do you see higher margins for the more energy-efficient products?

Other

Do you have any suggestions on ways to increase market penetration of energy-efficient windows?

Are there any industry experts or specific market actors that you would suggest we talk to?

Any other comments?

\section{Frame Manufacturers}

The Interviewee

Characterization of the Market

Current Status of Energy-Efficient Technologies in the Market

The Motivations and Drivers in the Industry
What is your role in your company?

Are you knowledgeable about your company's nonresidential windows product sales and marketing strategies?

How would you describe your company's market, in regards to windows?

Only makes frames? Integrated full service firm that also makes window frames? Makes complete windows (glazing with frame)? Installs windows?

What percent of your markets are nonresidential?

What are the most important industry trends today? New products, new materials, new competition, partnerships, daylighting, vertical or horizontal integration?

How are codes (ASHRAE 90.1, CA T24, regional PNW) or product standards (ANSI) influencing these trends?

How will these trends change in the next few years? Why?

What sort of challenges and opportunities do you see in the next few years? How about trends in window frame characteristics?

What major window frame types does your company produce? Aluminum unbroken? Thermally broken? Frames for argon fill? Any other groupings used?

What are the standard glazing sizes for your frames?

Any technologies available that you currently do not use? Why is it not used?

Any new technologies on the horizon?

Generally, where does your company get info on technical improvements, especially energy efficiency?

What industry trends do you think are having the greatest effect on energy-efficient windows sales/production?

What are the market drivers that determine the level of energy-efficient products that your company sells?

Price___ Codes___ Materials ___ Other

What are your major sales channels in respect to nonresidential products? Distributors? Sold to subsidiary that manufactures windows? Sold to subsidiary that installs windows? Other department? Window manufacturers? Glazing contractors? Specialty shops \%?

How do you promote and support your product and how far down the supply chain?

What are the major messages used to sell your window product? Such as reliability, quality, price, value, product selection, delivery time, energy efficiency?

How could energy efficiency fit in?

How are new products developed? 
Cost/Price of Energy-Efficient Technology

Other
Are ideas internally generated or are they a result of market demand?

A recent industry study estimated that only two-thirds of aluminum frames sold were thermally broken aluminum. In your opinion, what percent of the nonresidential market will be thermally broken aluminum in five years?

What is keeping thermally broken frames from being used on everything?

What is keeping advanced thermally broken designs from gaining market share?

The same study indicated that only $2 \%$ of the national market was triple glazing. Where do you estimate it to be in five years?

How does the production of energy-efficient window framing affect cost?

What is the incremental per linear foot cost of framing characteristics?

What are your pricing policies for energy-efficient frames compared to non-energy efficient frames?

What is the incremental pricing policy for the specific window characteristics?

Do you see higher margins for the more energy-efficient products?

Do you have any suggestions on ways to increase market penetration of energy-efficient windows?

Are there any industry experts or specific market actors that you would suggest we talk to?

Any other comments?

\section{Shop-Built Window Manufactures}

The Interviewee

Characterization of the Market
Current Status of Energy-Efficient Technologies in the Market
What is your role in your company?

Are you knowledgeable about your company's marketing and sales of the nonresidential windows that your company manufactures?

How would you describe your company's market?

Is this product mix a reaction to market growth or is your company actively pursuing different specialized markets?

Does your firm's market extend into site-built windows?

What percent of your markets are nonresidential?

How much of your nonresidential markets are custom vs. standard? Any specific sectors your company focuses on (e.g., public buildings, hotel/motel, office buildings, etc.)?

What are the most important industry trends today? New products, new competition, partnerships, daylighting, vertical or horizontal integration?

How are codes (ASHRAE 90.1, CA T24, regional PNW) or product standards (NFRC) influencing these trends?

How will these trends change in the next few years? Why?

What sort of challenges and opportunities do you see in the next few years?

How about trends in window characteristics?

What percentage of the windows that you specify are of this type?

How would you define a high efficiency window?

What major window types does your company produce?

Generally, where does your company get info on technical improvements, especially energy efficiency? 
Would you say process issues or market demand is determining the level of energyefficient features in your nonresidential window products?

Has this product mix been changing?

What has led to these changes?

What are the barriers to producing, promoting, and selling energy-efficient glazing features?

Producing: Capital investment costs in production line, quality control, shipping and warehousing, delivery issues?

Selling and promoting: Code does not require them, first costs, life-cycle costing -- a hard sell, lack of demand, lack of perceived need, insufficient track record, customers feel energy-efficient features are unreliable, unable to pass on higher costs of production?

Perceived costs vs. actual costs?

What are the non-energy benefits that are associated with energy-efficient glazings?

What benefits do you see?

Benefits accruing: Fewer callbacks, satisfied clients, greater recognition, staying ahead of the competition?

Benefits accruing to owner/developer: Less noise, less sun bleaching, greater tenant comfort, lower capital costs (e.g., energy-efficient windows allow for downsizing of HVAC system), higher rents, tenant retention (i.e., lower vacancy rates)?

What industry trends do you think are having the greatest effect on energy-efficient windows sales/production?

The Motivations and Drivers in the Industry

Cost/Price of Energy-Efficient Technology

Other
What are the market drivers that determine the product mix? Though reps? Distributors direct to glazing contractors? Retailers? Specialty shops?

How are your window frames distributed into the market?

Are ideas internally generated or are they a result of market demand?

How do you promote and support your product, and how far down the supply chain?

What are the major messages used to sell your window product? Such as reliability, quality, durability, ease of instillation, price, value, product selection, delivery time/availability, comfort, energy efficiency?

How could energy efficiency fit in?

How are new products developed? In-house R\&D, industry association-sponsored research, equipment manufactures, engineering firms?

A recent industry study estimated shop-built nonresidential windows at $17 \%$ of the national market. In your opinion, what percent of the nonresidential market will it be in five years?

Is anything keeping low-e from being used on all shop-built nonresidential windows?

Anything keep more advanced energy-efficient designs from gaining more market share? How does the production of energy-efficient windows affect cost?

What are your pricing policies for energy-efficient window compared to non-energy efficient windows?

Do energy-efficient windows have higher margins?

Do you have any suggestions on ways to increase market penetration of energy-efficient windows? 
Are there any industry experts or specific market actors that you would suggest we talk to?

Any other comments?

\section{Laminate and Applied Film Manufactures}

The Interviewee

Characterization of the Market

Current Status of Energy-Efficient Technologies in the Market

The Motivations and Drivers in the Industry

Cost/Price of Energy-Efficient Technology

Other
What is your role in your company?

Are you knowledgeable about your company's marketing and sales of nonresidential glazing products?

How would you describe your company's film market?

What percent of your market is nonresidential?

Is this product mix a reaction to market growth or is your company actively pursuing different specialized markets?

What are the most important industry trends today? New products, new competition, partnerships, daylighting, vertical or horizontal integration, new technologies, new materials?

How are codes (ASHRAE 90.1, CA T24, regional PNW) or product standards (NFRC) influencing these trends?

How will these trends change in the next few years?

What sort of challenges and opportunities do you see in the next few years?

What are the major film technologies that effect energy efficiency that your company produces?

Any new technologies on the horizon?

What industry trends are having the greatest effect on energy-efficient film sales/production?

What are the barriers to producing, promoting and selling energy-efficient films?

How is your nonresidential film product sold, or distributed into the market? Through reps? Distributors direct to glazing contractors? Window manufacturers? Contractors?

How do you promote and support your product, and how far down the supply chain?

What are the major messages used to sell your (nonresidential?) film products? Such as reliability, quality, price, value, product selection, delivery time, energy efficiency?

How are new products developed? In-house R\&D, industry association-sponsored research, equipment manufactures, engineering firms.

How does the production of energy-efficient films affect window cost?

What are your pricing policies for energy-efficient films compared to non-energy efficient films?

Do energy-efficient features have higher margins?

Do you have any suggestions on ways to increase market penetration of energy-efficient windows?

Are there any industry experts or specific market actors that you would suggest we talk to? 